\title{
THE WESTWARD THERMOSPHERIC JET-STREAM OF THE EVENING AURORAL OVAL
}

\author{
D. REES, T. J. FULLER-ROWELL, M. F. SMITH and R. GORDON \\ Department of Physics and Astronomy, University College London, Gower Street, London, \\ WC1E 6BT, U.K.
}

T. L. KIULEEN and P. B. HAYS

Space Physics Research Laboratory, University of Michigan, 2455 Hayward, Ann Arbor, M1 48109, U.S.A.

and

N. W. SPENCER, L. WHARTON and N. C. MAYNARD

Goddard Space Flight Center, Greenbelt, MD 20771, U.S.A.

(Received in final form 12 October 1984)

\begin{abstract}
One of the most consistent and often dramatic interactions between the high latitude ionosphere and the thermosphere occurs in the vicinity of the auroral oval in the afternoon and evening period. lonosphericions, convected sunward by the influence of the magnetospheric electric field, create a sunward jetstream in the thermosphere, where wind speeds of up to $1 \mathrm{~km} \mathrm{~s}^{-1}$ can occur. This jet-stream is nearly always present in the middle and upper thermosphere (above $200 \mathrm{~km}$ altitude), even during periods of very low geomagnetic activity. However, the magnitude of the winds in the jet-stream, as well as its location and range in latitude, each depend on geomagnetic activity. On two occasions, jet-streams of extreme magnitude have been studied using simultaneous ground-based and satellite observations, probing both the latitudinal structure and the local time dependence. The observations have then been evaluated with the aid of simulations using a global, three-dimensional, time-dependent model of thermospheric dynamics including the effects of magnetospheric convection and particle precipitation. The extreme events, where sunward winds of above 800 $\mathrm{m} \mathrm{s}^{-1}$ are generated at relatively low geomagnetic latitudes $\left(60-70^{\circ}\right)$ require a greatly expanded auroral oval and large cross-polar cap electric field $(\sim 150 \mathrm{kV})$. These in turn are generated by a persistent strong Interplanetary Magnetic Field, with a large southward component. Global indices such as $K_{p}$ are a relatively poor indicator of the magnitude and extent of the jet-stream winds.
\end{abstract}

\section{INTRODUCTION}

There have been very few observations of neutral wind velocities in the Earth's upper thermosphere in excess of about $250-300 \mathrm{~m} \mathrm{~s}^{-1}$, except for those made in regions close to or within the geomagnetic polar caps and the auroral ovals. Fuller-Rowell and Rees (1980), Rees et al. (1980) and Dickinson et al. (1981) have shown, using theoretical models, that the heat input from solar u.v. and e.u.v. radiation should not drive winds in excess of about $200 \mathrm{~m} \mathrm{~s}^{-1}$. When high latitude (geomagnetic) energy and momentum sources are taken into account (Fuller-Rowell and Rees, 1980; Rees et al., 1980; Roble et al., 1982), it is found that the $250-300 \mathrm{~m} \mathrm{~s}^{-1}$ winds observed at middle latitudes (equatorward during the midnight period) can be generated by the combination of solar and geomagnetic forcing.

Recent data from the Fabry-Perot interferometer (FPI)(Hays et al., 1981) and the Wind and Temperature sensor (WATS, Spencer et al., 1981) of the Dynamics Explorer-2 (DE-2) satellite have shown that signifi- cantly higher wind speeds $\left(300-500 \mathrm{~m} \mathrm{~s}^{-1}\right)$ are a persistent feature of the auroral and polar regions even in periods of relatively low geomagnetic activity. Sunward winds occur within the auroral oval, and are strongest usually in the $12.00-22.00$ M.L.T. (magnetic local time) part of the auroral oval, while anti-sunward winds occur over the entire geomagnetic polar cap. Killeen et al. (1983), Rees et al. (1983a), Roble et al. (1983) and Hays et al. (1984) have presented and discussed the data from $D E-2$ both from individual orbits, and on the basis of statistical analyses of data from large numbers of orbits. It is clear that this polar wind circulation is driven by ion drag from the two-cell ion convection imposed on the polar regions by the magnetosphere.

There are a number of reports in the literature of significantly higher thermospheric wind speeds that have been observed either by ground-based FabryPerot interferometers (FPI) or by rocket-borne chemical releases at high geomagnetic latitudes and/or during strong geomagnetic disturbances. Rees 
(1971a,b); Meriwether et al. (1973); Lloyd et al. (1972); Hays et al. (1979); Rees et al. (1980); Mikkelson et al. (1981); Heppner and Miller (1982); Hernandez and Roble (1978a, b; 1982) and Rees et al. $(1982,1983 \mathrm{~b})$ have reported wind speeds of $300 \mathrm{~m} \mathrm{~s}^{-1}$ or more which can be directly related to elevated geomagnetic activity.

In this paper, the discussion will be limited to one specific class of phenomena occurring in the post noon and pre-magnetic midnight (12.00-22.00 M.L.T.) part of the auroral oval. All the experimental observations referenced previously, except Lloyd et al. (1972) and Hernandez and Roble $(1978 a, b)$ where the observations were made at relatively low geomagnetic latitudes, describe the frequent occurrence of fast westward or sunward winds within this region, which are thus directly contrary to the sense of winds driven by global solar u.v. and e.u.v. heating. Sunward winds occur in this region even at a low level of geomagnetic activity $\left(1<K_{p}<2\right)$ (Rees et al., 1985a). At extremely low levels of geomagnetic activity, sunward winds may not be observed in this local time period and in the vicinity of the mean auroral oval, but this is most likely due to the poleward contraction of the auroral oval away from stations located to observe the 'mean' auroral oval (Rees et al., 1985a).

This conclusion is reinforced by the $D E-2$ wind data. Almost never does the zonal wind observed by $D E$-2 fail to turn sunward between the anti-sunward flowing wind regime of the polar cap and the anti-sunward flowing wind regime of the low and middle latitude region, as the satellite crosses a jet of sunward fowing plasma in the auroral oval in the magnetic local time region $12.00-22.00$.

We will describe this region of the thermospheric wind pattern as the westward thermosphericjet-stream of the evening auroral oval.

The primary driving force producing sunward winds in the 12.00-22.00 M.L.T. part of the auroral oval is ion drag. Parcels of neutral gas are entrained in a region of fast sunward ion flow, part of the two-cell magnetospheric plasma convection pattern imposed on the geomagnetic polar region (e.g. Heppner, 1977). The combination of driving forces and the mechanism of the thermospheric response has been analysed in some detail by Fuller-Rowell and Rees (1981) and Fuller-Rowell et al. (1984), and by Rees et al. (1983a). Sunward winds are endemic in this region as illustrated by the wind data presented by Killeen et al.(1983), Rees et al. (1983a) and Hays et al. (1984) from the DE-2 satellite. These results also indicate that the location of the region of sunward winds and their magnitude respond to the changing location and magnitude of the high latitude ion convection pattern.

Observations of wind speeds in this evening jet stream from ground-based FPIs located in the vicinity of the auroral oval and during moderately disturbed geomagnetic conditions (Rees et al., 1985a) are generally in the range of $200-500 \mathrm{~m} \mathrm{~s}^{-1}$. As seen by the WATS instrument of $D E-2$, sunward wind velocities of 400 $600 \mathrm{~m} \mathrm{~s}^{-1}$ are the most common range within this region.

The discrepancy is almost certainly due to a combination of two factors. Firstly, there is the superior sampling ability of the WATS instrument on the polar orbiting $D E-2$, which will always be able to locate the region of fastest sunward winds, which is not always possible from a fixed ground based instrument with a pre-determined scan pattern. The peak wind speed may occur between the widely $(400 \mathrm{~km})$ separated points sampled typically by a ground-based instrument. The peak winds may also occur poleward or equatorward of the entire region sampled by the ground-based instrument. Secondly, the thermospheric wind velocity at $320-350 \mathrm{~km}$ altitude (where WATS samples) will generally be higher than that integrated by the volume emission rate of the forbidden oxygen red line over the lower altitude range of approx. $220-300 \mathrm{~km}$ and thus effectively sampled by the ground based instrument.

Despite the considerable interest in this comparison, the discussion in this paper will concentrate on the topic of the westward jet stream.

On rare occasions, the wind magnitudes observed in this region are much larger than $500-600 \mathrm{~m} \mathrm{~s}^{-1}$. Rees et al. $(1982,1983 \mathrm{~b})$ have reported winds of more than 800 $\mathrm{m} \mathrm{s}^{-1}$ from a ground-based FPI (GBFPI) located in Northern Scandinavia. During the life-time of $D E-2$, two particular instances of extreme winds in this region were recorded both by the satellite, as it crossed the northern polar region, and by the GB FPI in Northern Scandinavia, on 12 December 1981 and 17 December 1982.

In these instances, the WATS and FPI instruments on the $D E-2$ satellite were able to determine the large scale wind structure, and to describe the ion-drag driving forces creating unusually large wind speeds, while the GB FPI recorded the development and recovery of the thermospheric events at a fixed location on the rotating earth.

The UCL 3D-TD global thermospheric model has been used to simulate the response of the thermosphere during a period when the magnetosphere and ionosphere were being driven very hard as a result of a large value of the interplanetary magnetic field (IMF) with, additionally, a strong southward component. At such times, the auroral oval is expanded equatorward from its average location, and there is a large crosspolar cap electric potential $(120-150 \mathrm{kV}$ in these 
instances). The combined thermospheric wind observations from the satellite and the GBFPI located in Northern Scandinavia (Rees et al, 1981, 1983b, 1985a) have been used to test the validity of the inputs to the model, and to examine the overall thermospheric effects of these rare disturbances.

\section{THE OBSERVATIONS}

Thermospheric wind observations from the polarorbiting NASA DE-2 satellite are made by the FabryPerot interferometer (FPI) (Hays et al, 1981) which measures the meridional wind component from the Doppler shift of the OI $630 \mathrm{~nm}$ emission line of the upper thermosphere, and by the wind and temperature sensor (WATS) (Spencer et al., 1981, 1982) which mcasures the in situ cross-track wind specd (zonal wind component) by using a modified mass-spectrometer. Killeen et al. (1982) have shown how these two independent data sets may be combined to obtain a neutral wind vector profile along the satellite path at altitudes of about $320-350 \mathrm{~km}$ for regions of the orbit near perigee from the polar-orbiting satellite. The GBFPI operated from the Kiruna Geophysical Institute during both the periods of coincident observations has been described by Rees et al. (1981, 1983b, 1985a).

\section{Event A-12 December 1981}

On 12 December 1981 , perigee $(320 \mathrm{~km})$ of the $D E-2$ satellite was in the vicinity of the North Pole, and two successive orbits $(1943,1944)$ crossed the evening auroral oval at approx. 16.00 U.T. and 17.40 U.T., at longitudes of $18 \mathrm{E}$ and $9 \mathrm{~W}$ respectively. Wind velocity vectors for these two orbits are shown in Figs. 1 and 2 respectively (combined FPI and WATS observations), covering the north polar region. In Fig. 3 the highresolution zonal wind components from WATS are shown for orbit 1943. In the evening auroral oval in orbits 1943 and 1944, the westward wind (sunward) approached $800 \mathrm{~m} \mathrm{~s}^{-1}$, over a range of close to $10^{\circ}$ of latitude. The latitude range of the maximum westward winds extended equatorward to the relatively low geomagnetic latitude of $60^{\circ}$, and these velocities exceed

\section{DE-FPI/WATS NEUTRAL WIND VECTORS}

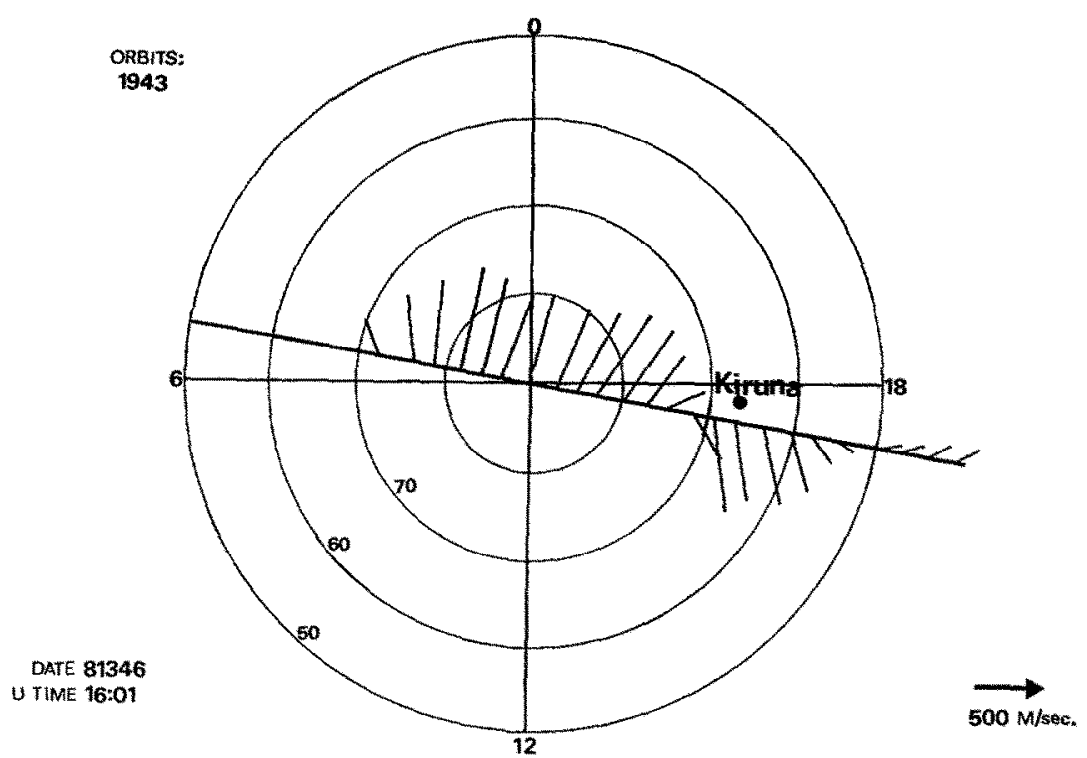

FIG. 1. NiUTRAL WIND VELOCTT VECTORS MEASURED BY DE-2 COMBINING FPI AND WATS DATA FOR ORBT 1943, ABOUT 16.00 U.T. ON 12 DECEMBER 1981, OVER THE NORTH POLE.

Maximum anti-sunward velocities in the polar cap (i.e. above about $72^{\circ}$ geographic latitude in this plot) are about $900 \mathrm{~m} \mathrm{~s}^{-1}$, and maximum westward (or sunward) velocities in the dusk auroral oval $\left(55-72^{\circ}\right.$ at $17.00 \mathrm{~L} . \mathrm{T}$. in this plot) are between 800 and $900 \mathrm{~m} \mathrm{~s}^{-1}$ at about $68^{\circ}$ geographic latitude. The sunward jet-stream in the dusk auroral oval has expanded equatorward to the unusually low latitude of $55^{\circ}$ geographic ( 55 geomagnetic) compared with a mean value of about $65^{\circ}$ at this Local Time and geographic longitude. The local solar time (in hours) is noted around the polar dial, and the location of Kiruna relative to the satellite track is also noted. 


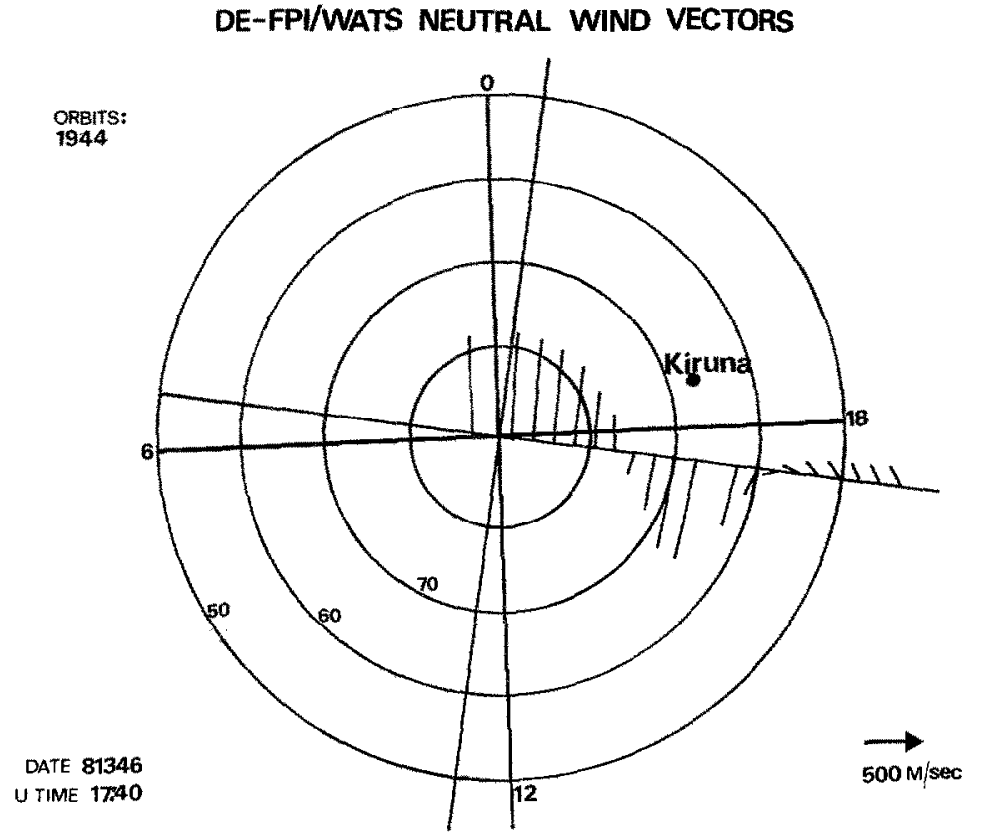

Fig. 2. Neutral WIND veloctry vectors measured by $D E-2$ COMBINING FPI and WATS DATA FOR ÓRBT 1944, About 17.45 U.T. ON 12 December 1981, over THE North Pole.

Maximum anti-sunward velocities in the polar cap (i.e. above about $75^{\circ}$ geographic latitude in this plot) are about $800 \mathrm{~m} \mathrm{~s}^{-1}$, and maximum westward (or sunward) velocities in the dusk auroral oval $\left(60-75^{\circ}\right.$ at $17.00 \mathrm{~L}$.' $T$. in this plot) are about $700 \mathrm{~m} \mathrm{~s}^{-1}$. In geographic and geomagnetic coordinates, the auroral oval has retreated poleward at the end of the maximum disturbance, although the maximum velocities have only decreased slightly. The local time (in hours) is noted around the polar dial.

by a factor of more than 2 those reported for more average geomagnetic activity by Rees et al. (1983a) and Hays et al.(1984). During both passes, the anti-sunward wind over the polar cap is also high $\left(600 \mathrm{~m} \mathrm{~s}^{-1}\right)$. The WATS high resolution data show also that there is considerable detail in the zonal wind response, both in the auroral oval and in the polat cap. Note also the double maximum, at 60 and $67^{\circ}$ latitude, in the sunward (westward) zonal wind in the evening auroral oval.

In Figs. 4 and 5, the meridional and zonal winds observed from the GB FPI at Kiruna are shown, for the period between 14.00 U.T. (12 December) and 06.00 U.T. (13 December), a period of excellent observing conditions. These observations were made using the OI $630 \mathrm{~nm}$ emission line. At the start of observations the westward zonal wind observed both to the East and to the West of Kiruna was already above $400 \mathrm{~m} \mathrm{~s}^{-1}$, and it increased steadily until a peak value of over $850 \mathrm{~m} \mathrm{~s}^{-1}$ was reached close to 16.00 U.T. to the West of Kiruna. The wind value to the East was somewhat lower, about $550 \mathrm{~m} \mathrm{~s}^{-1}$. Since the observation to the geographic West is about $2^{\circ}$ higher geomagnetic latitude than that to the East, the two observations indicate a gradient with geomagnetic latitude similar to that observed over the same latitude range by the WATS instrument. The westward wind observed in the West by the GBFPI (height-integrated) agrees well with the in situ WATS measurement at almost exactly the same time, longitude and latitude, and the lower magnitude observed in the East (at lower geomagnetic latitude and further from the $D E-2$ track) may be associated with the rather lower zonal flow observed by WATS near $65^{\circ}$ latitude (Fig. 3).

Following 16.00 U.T., the zonal wind velocity decreased steadily and eventually reversed direction to become eastward after 20.00 U.T., just before magnetic midnight at Kiruna (normally about 21.00 U.T.).

In contrast to the large decrease in the magnitude of the westward wind which occurred at Kiruna between 16.00 and 17.30 U.T., WATS observed only a slight decrease in the magnitude of the westward wind between orbits 1943 and 1944. There was, however, a significant migration of the location of the peak westward (sunward) zonal wind to higher geomagnetic latitude in the 100-min interval between the two consecutive orbits, which will be discussed later. 


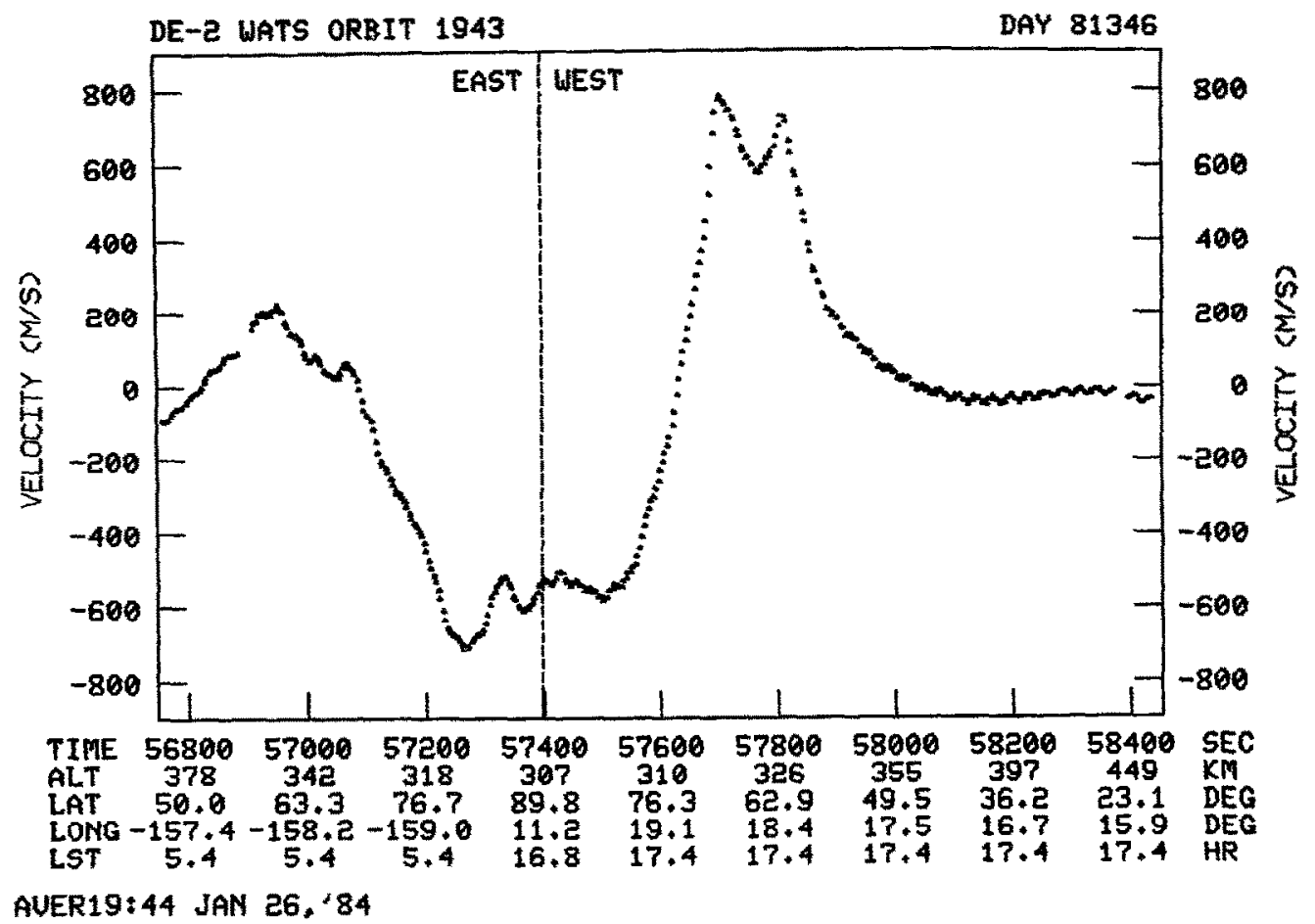

FIG. 3. THE DETALLD OBSERVATIONS OF THE ZONAL WIND FROM DE-2 measured by the WATS instrument for orbit 1943 (16.00 U.T. 12 December 1981).

The dusk auroral oval is located on the right hand side of the diagram, where there are two peaks in the sunward wind velocities, one at 69 geographic latitude, and a second, with slightly lower velocity at $60^{\circ}$ latitude. Considerable structure can also be observed in the anti-sunward wind pattern over the polar cap. This orbit traversed a longitude of about $18^{\circ}$ East, and thus the satellite passed only about $100 \mathrm{~km}$ West of Kiruna. Meridional winds on the dusk side of the polar cap, throughout the dusk auroral oval and toward midlatitudes on the evening side of the orbit are quite strongly equatorward at this time.

During the afternoon and early evening period the meridional wind to the North of Kiruna was very small, and to the South of Kiruna, it varied between 50 and $150 \mathrm{~m} \mathrm{~s}^{-1}$ (equatorward). At the time of the $D E-2$ overpass on orbit 1943, the ground-based FPI indicated weak equatorward winds (less than $30 \mathrm{~m} \mathrm{~s}^{-1}$ ) to the North of Kiruna (average at $71 \mathrm{~N}$ ) contrasting with about $130 \mathrm{~m} \mathrm{~s}^{-1}$ equatorward to the South of Kiruna (about $63^{\circ} \mathrm{N}$ latitude). The $D E-2$ FPI, which integrates over the order of a $1000 \mathrm{~km}$ path due to the limb-scanning geometry, measured an equatorward wind component of the order of $100 \mathrm{~m} \mathrm{~s}^{-1}$ throughout the latitude band $70-60^{\circ}$, in good agreement with the ground-based observations.

Stronger and more variable equatorward winds were observed at Kiruna after 19.00 U.T., the local time when the zonal winds are changing from westward to eastward. After 21.00U.T, there were a number of quite abrupt increases of both meridional winds (southward) and zonal winds (eastward) in response to short periods of more intense auroral and magnetic activity later in the night. The highest wind speeds only reached 400 $\mathrm{m} \mathrm{s}^{-1}$ (castward and equatorward components) close to 22.00 U.T., and then decreased later in the night. Another relatively large disturbance occurred about 03.00 U.T. the next morning (13 December), although the wind response $\left(250 \mathrm{~m} \mathrm{~s}^{-1}\right.$ eastward, $150-200 \mathrm{~m} \mathrm{~s}^{-1}$ southward) was much smaller than that during the major westward wind disturbance of the previous evening.

The Kiruna magnetic record for this period is shown in Fig. 6, while the ISEE-3 record of the IMF during the same period is shown in Fig. 7. The ISEE-3 data showed a strong and persistent southward component of the IMF, at a time of a moderately strong total IMF [B] field strength, a situation which persisted until 20.00 U.T. The magnetic record from Kiruna shows that a strong and long-lasting positive bay disturbance 

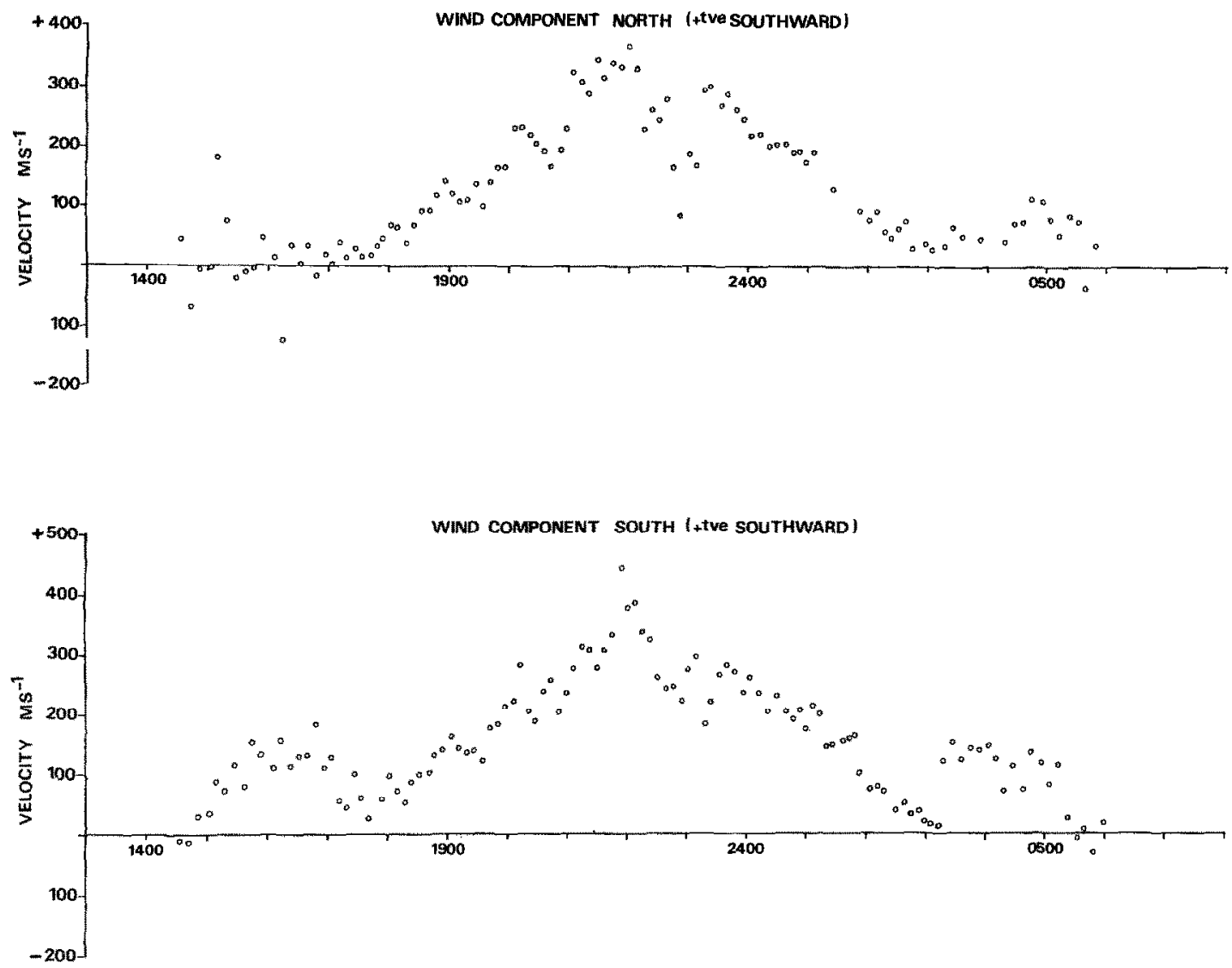

DEC $12 / 131981$

FiG. 4. THE MERIDIONAL NEUTRAL WIND COMPONENTS ORSER VED From KIRUNA GEOPHYSICAL INSTTTUTE (KGI) BETWEEN 14.00 U.T. (12 DECEMRER 1981) AND 06.00 U.T. (13 DECEMBER 1981).

The observations marked "North" are made with the FPI looking toward the North from KGI, and are thus at a location approx. $400 \mathrm{~km}$ poleward of Kiruna (approx. $22^{\circ} \mathrm{E}, 71^{\circ} \mathrm{N}$ ). Those marked "South" are made looking South, at a location approx. $22^{\circ} \mathrm{E}$ and $64^{\circ} \mathrm{N}$. Meridional winds at the times of the orbits 1943 and 1944 are small and equatorward, approximately zero to the North of Kiruna, and $100 \mathrm{~m} \mathrm{~s}^{-1}$ southward $400 \mathrm{~km}$ to the South of Kiruna. The detailed agreement with the FPI data for orbit 1943 is thus very good, with FPI showing an average of about $60 \mathrm{~m} \mathrm{~s}^{-1}$ equatorward in the region between 70 and $65^{\circ}$ North.

started about 12.00 U.T., which peaked at about 450 $\mathrm{nT}$, close to the $D E-2$ overpass (orbit 1943) and the time of the peak westward winds observed from Kiruna, about 16.00 U.T.

Data from the Vector Electric Field Instrument (VEFI) on DE-2 (Maynard et al., 1982) for the two orbits 1943 and 1944 are shown in Figs. 8 and 9. The single horizontal component of electric field measured along the orbit track has been rotated and plotted in the direction of the corresponding convection ion velocity. Note that these arrows do not represent the total electric field, only that component which was measured. Comparison of Figs. 1 and 2 and Figs. 8 and 9 show that the poleward and equatorward boundaries of the strong northward electric fields (westward ion drifts) seen by VEFI correspond closely to the regions of strong westward winds in the dusk auroral oval. The peak westward ion drift approached $2 \mathrm{~km} \mathrm{~s}^{-1}$, with two distinct maxima, at about 68 and $62^{\circ}$ geomagnetic latitude (orbit 1943). This double maximum is very similar to that observed in the WATS data (Fig. 3), however, the highest speed ion flows occurred in the lower latitude peak, opposite to that of the winds. In the second pass (Fig. 9), the convection ion flow was 


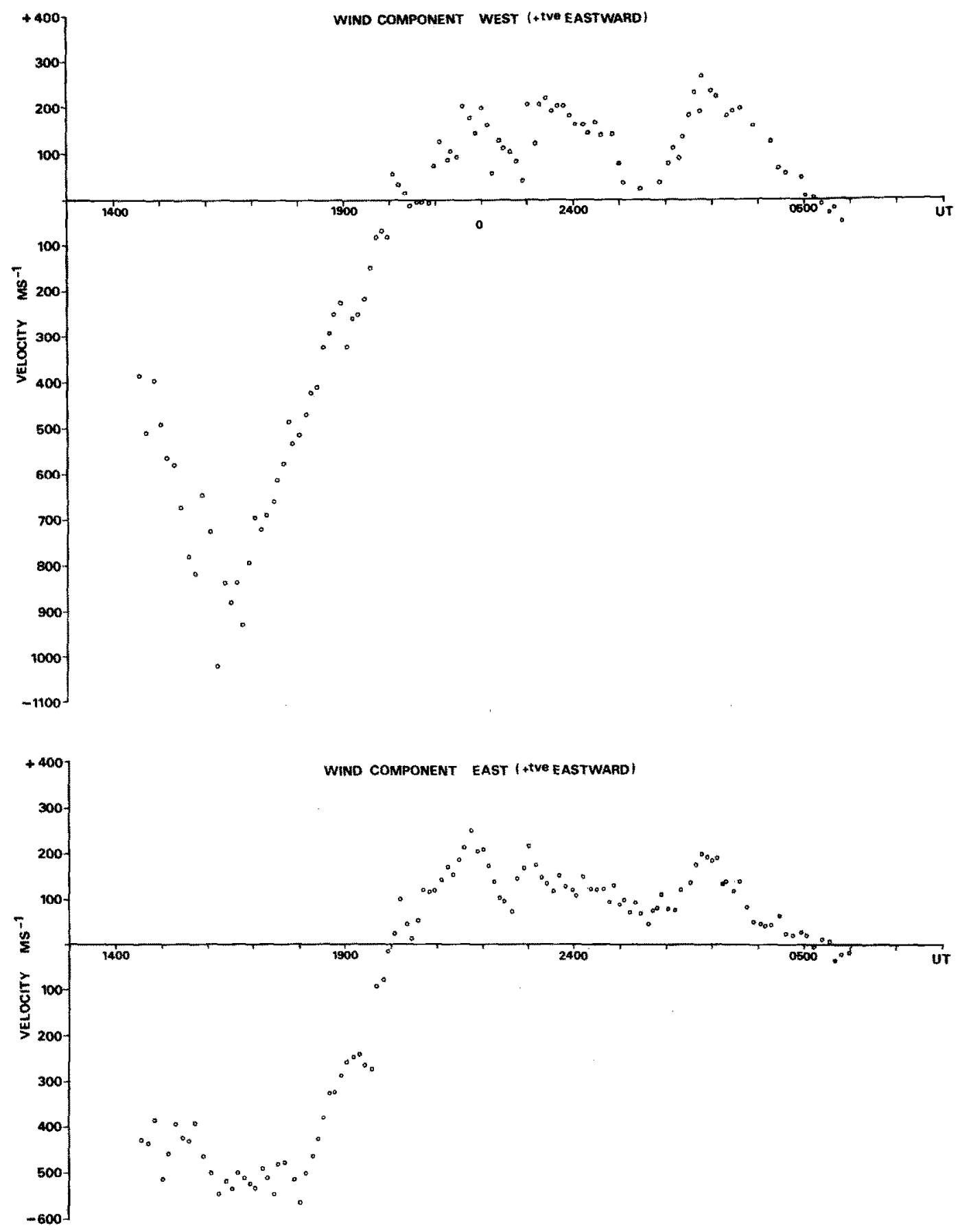

\section{DEC $12 / 131981$}

Fig. 5. THE ZONAL NEUTRAL WIND COMPONENTS OBSER VED FROM KGI BETWEEN 14.00 U.T. (12 DECEMBER 1981) AND 06.00 U.T. (13 DECEMBER 1981).

Zonal winds measured to the West of Kiruna are from a region which is about $68^{\circ}$ North and $12^{\circ}$ East, geographic, while the observing region to the East is abouf $66^{\circ} \mathrm{N}, 32^{\circ} \mathrm{E}$. The region observed by the FPI to the West is about $3^{\circ}$ higher geomagnetic latitude than the region observed to the East. The FPI observations to the West at 16.00 U.T. correspond to the peak westward velocities observed by WATS at $69^{\circ} \mathrm{N}$. The lower wind magnitude at 16.00 U.T. Lo the East can be assuciated with the minimum westward wind observed by WATS at about $65^{\circ} \mathrm{N}$ geographic latitude. By the time of the second $D E-2$ overpass, some $400 \mathrm{~km}$ West of Kiruna, the zonal winds observed to the Fast and to the West of KGI had both decreased to $500 \mathrm{~m} \mathrm{~s}^{-1}$. Both observing Incations were equatorward of the region of maximum winds seen hy WATS at this time. I ater in the night, the zonal winds decrease steadily, and change sense to eastward just after $20.00 \mathrm{UT}$. 


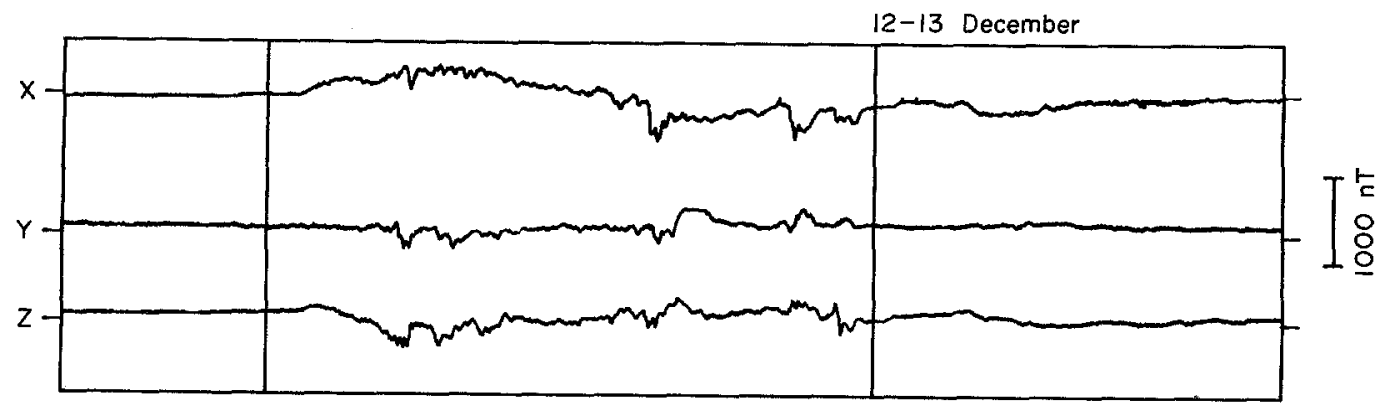

Fig. 6. Ground-BASEd MAGNeTOMETER RECORDS From KIRUNA (SWEDEN) FOR THE PERIOD 08.00 U.T. 12 DECEMBER 1981 To 08.00 U.T. 13 DECEMBER 1981.

The magnetic field data shows the long-lasting positive bay disturbance between 13.00 U.T. and 18.00 U.T., associated with the enhanced eastward electrojet of an equatorward-expanded afternoon auroral oval.

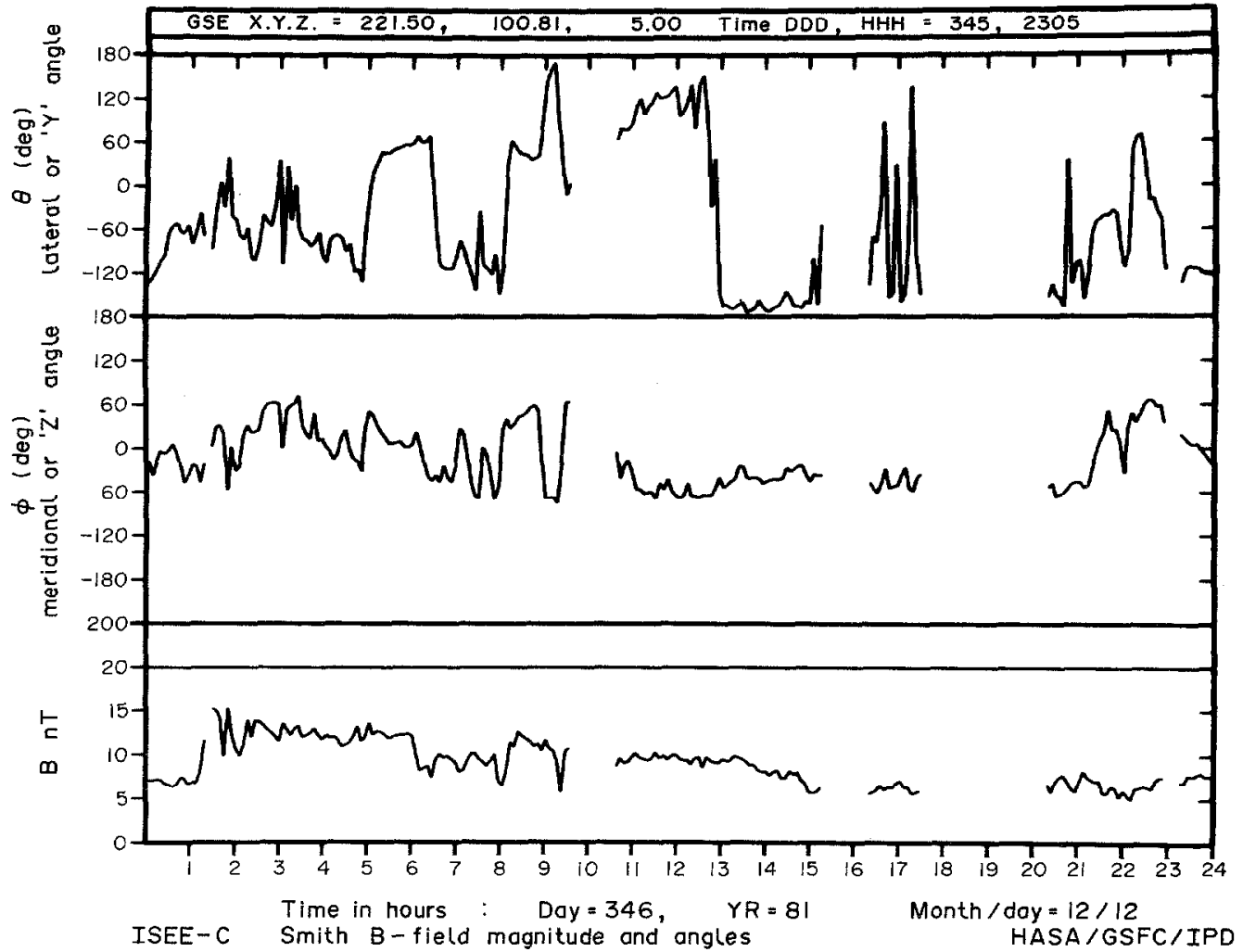

FIG. 7. OBSERVATIONS OF THE INTERPLANETARY MAGNETIC FIELD(IMF) FROM THE ISEE-3 SPACECRAFT DURING THE PERIOD 00.00 U.T. TO 24.00 U.T. ON 12 DECEMBER 1981.

The ISEE-3 spacecraft was some distance from the direct Sun-Earth line at this time. There was a strong southward $(B Z)$ component of the IMF between about 08.00 U.T. and 21.00 U.T., and a negative $B Y$ component, in the main, after 13.00 U.T. The total magnitude of the IMF (B) increased sharply at 01.50 U.T., and then decreased steadily until 15.00 U.T., after which it stayed relatively constant at a value above a "quiet" level, but only half of the value between 01.50 and 13.00 U.T. The triggering of the strong eastward electrojet and expanded auroral oval appears to have been due to the southward turning IMF about 10.00U.T., coupled with the strong total IMF before this time and for the next $3-4 \mathrm{~h}$. 


$\begin{array}{llllllll}\text { DE-B } & \text { VEFI } & & 12 \text { DEC } 1981 & \text { DAY } 346 & \\ & \text { CRBIT } & 1943 & 15: 45: 4 & \text { TO } & 16: 8: 54 & \text { UT }\end{array}$

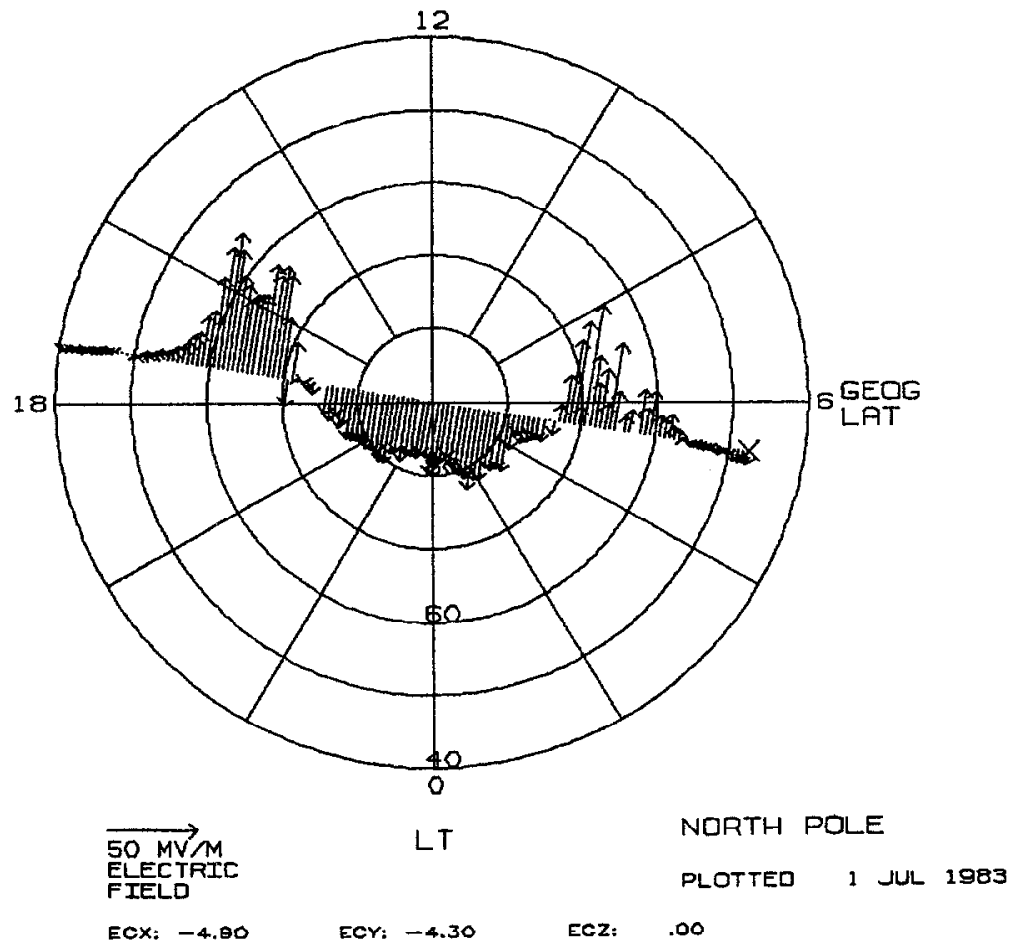

Fig. 8. POlar Plot Of THE dATA From the VeCtOR Electric Field INSTRument (VEFI) OF DE-2 FOR THE NORTH POLAR PASS OF ORBIT 1943 (16.00 U.T. 1981).

The figure shows the electric field component perpendicular to the spacecraft track rotated into the direction of the equivalent ion velocity. The sunward convection regions of the dusk and dawn crossings of the auroral oval show that the oval was expanded considerably equatorward from its mean location, and both the sunward velocities in the oval and the anti-sunward velocities of the polar cap are considerably stronger than normally occurs. The total cross-polar cap electric potential inferred from these data, allowing for the geometry of this crossing of the geomagnetic polar cap is $150 \mathrm{kV}$. This compares with an average "moderately disturbed" value of $80 \mathrm{kV}$, and a typical "quiet" value of about $20-40 \mathrm{kV}$.

reduced, and the auroral oval has contracted poleward. Thermal plasma densities and electron precipitation data from these same orbits (Brace, private comm., 1983; Winningham, private comm., 1983) and from the NOAA 6 and 7 satellites during the same period (Evans, D. private comm., 1984), indicate that there was a strong enhancement of magnetospheric precipitation and thus plasma density associated with the northern (polcward) part of the dusk auroral oval. In the equatorward part of the dusk oval as defined by strong westward convection, the enhancement was much less pronounced.

\section{Event B-17 December 1982}

A second event of this spectacular nature occurred on 17 December 1982. At 08.05 U.T. there was a strong
Storm Sudden Commencement (SSC) which can be seen in the magnetic record from Kiruna (Fig. 10). The IMF record from ISEE 3(Fig. 11) shows that there was a sudden increase in the IMF strength at 08.00 U.T., to the high value of $20 \mathrm{nT}$, which persisted until 19.00 U.T. There was also a large southward component until 15.00 U.T. Figure 12 shows the $D E-2$ WATS data at 11.30 U.T. for the north polar pass 7573, which crossed the dusk auroral oval about 18.00 L.S.T. There was again a large westward wind component exceeding $600 \mathrm{~m} \mathrm{~s}^{-1}$ throughout the afternoon auroral oval which was expanded equatorward similarly to the situation on 12 December 1981. The wind vectors from the combined FPI and WATS data for this pass are shown in Fig. 13. Strong $\left(600-800 \mathrm{~m} \mathrm{~s}^{-1}\right)$ anti-sunward winds occurred across the polar cap as were observed in orbit 1943. 


$\begin{array}{lllllll}\text { DE-B } & \text { VEFI } & 12 \text { DEO } 1981 & \text { DAY } 346 & \\ \text { ORBIT } & 1944 & 17: 24: 36 & \text { TO } 17: 45: 26\end{array}$ UT

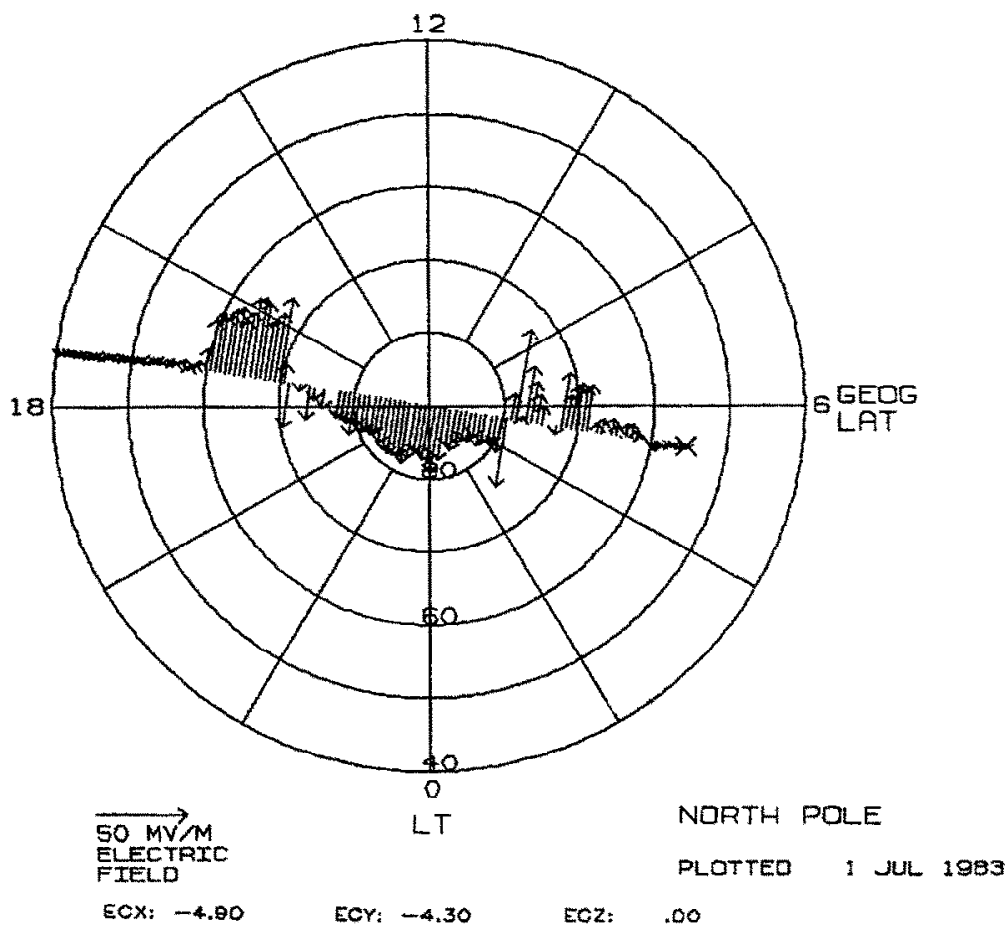

Fig. 9. Polar plot of the data fRom the Vector Electric Fitlo Instrument (VEFI) OF DE-2 TOR ORTIT 1944 (17.60 U.T. 1981).

North Pole data. The data shows the equivalent ion velocities perpendicular to the spacecraft track. The sunward convection regions of the dusk and dawn crossings show that the auroral oval has contracted poleward compared with orbit 1943, 100 min earlier, and that the mean and peak ion flow velocities have also decreased markedly. The size of the auroral oval, and the ion flows are, however, still both larger than average, and the cross-polar cap potential at this time is about $100 \mathrm{kV}$.

In Fig. 14 (A and B) the wind response observed at Kiruna is shown from the start of observations at 13.30 U.T. (local twilight). Considering the magnetic record and the evolution of the 12 December event, it is possible that the peak thermospheric wind response occurred prior to the start of GBFPI observations. Nevertheless, the peak observed winds of over 900 $\mathrm{m} \mathrm{s}^{-1}$ directed between westward and northwestward,

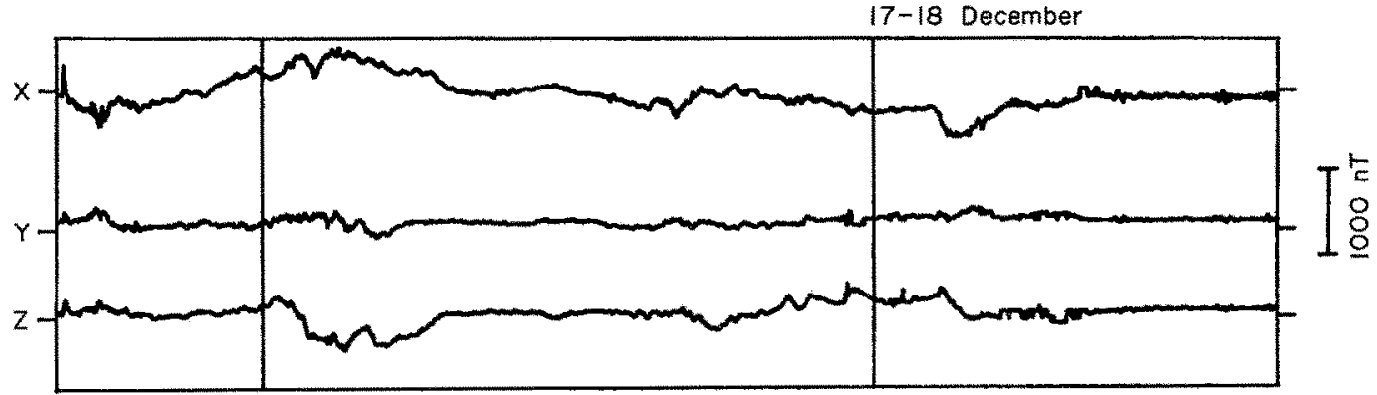

FIG. 10. GROUND-BASED MAGNETOMETER RECORDS FROM KIRUNA (SWEDEN) FOR THE EVENT OF 17 DECEMBER 1982.

The magnetic field data shows a strong eastward electrojet starting about 10.00 U.T. reaching a peak disturbance between 13.00 and 14.00 U.T, and steadily decreasing afterwards until about 17.00 or 18.00 U.T. At Kiruna, the peak of this disturbance was about $+850 \mathrm{nT}$, unusually large for a positive bay disturbance. 
The westward thermospheric jet-stream of the evening auroral oval

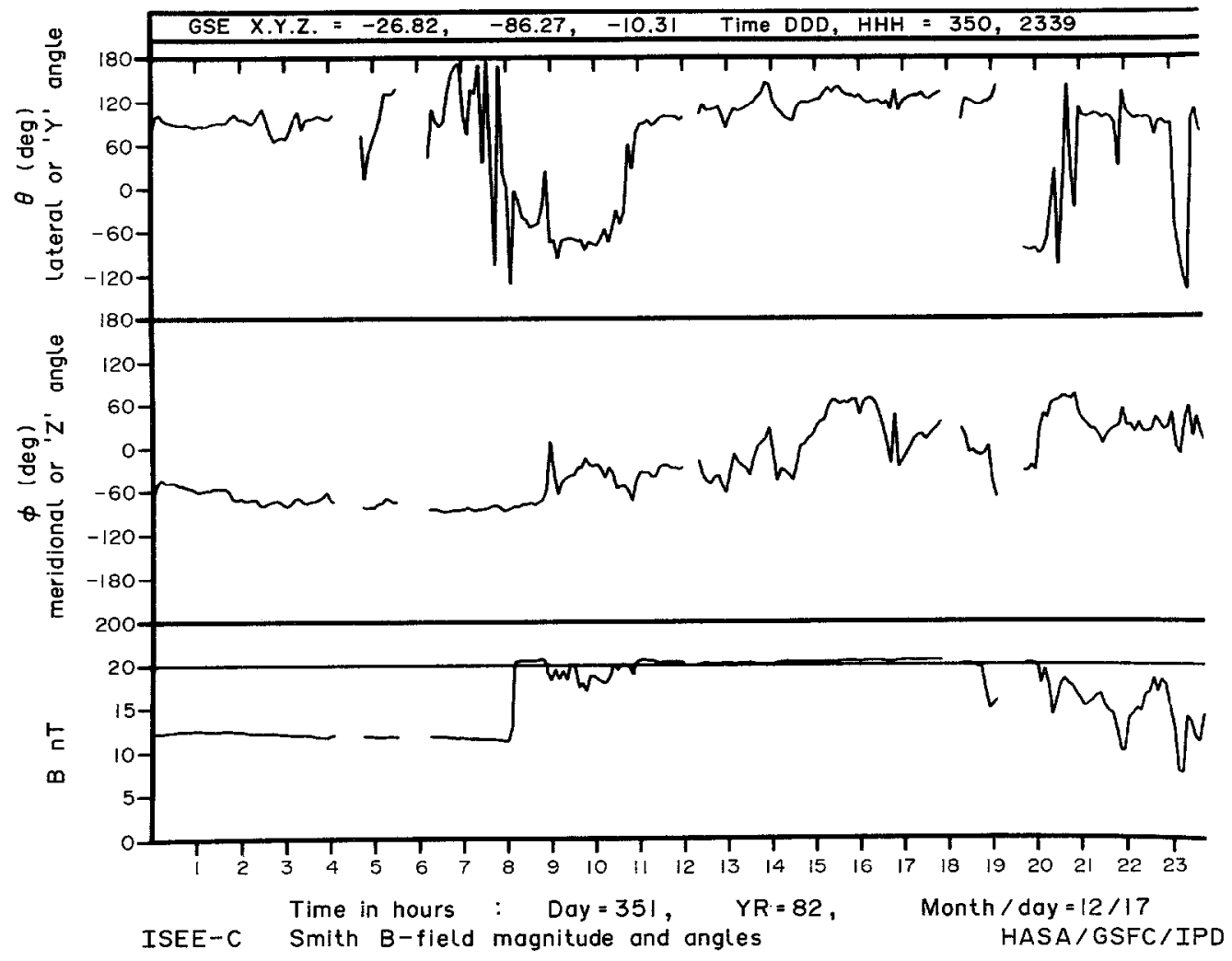

FIG. 11. THE RECORD OF THE IMF FROM ISEE-3 FOR THE PERIOD 00.00 U.T. TO 24.00 U.T. ON 17 DECEMBER 1982. A very strong solar wind "shock" was observed about 08.00 U.T., which was also observed as an SSC by the ground-based magnetometers. The IMF $B Z$ was strongly southward until 14.00 U.T., driving the geomagnetic disturbance until $B Z$ turned positive (northward) about 14.00 U.T. The magnitude of the ground-level magnetic disturbance decreased sharply after 14.00 U.T., although the total IMF “ $B$ " remained very high until after 24.00 U.T. Except for a negative excursion between 08.00 and 11.00 U.T., during the build-up of the geomagnetic disturbance, the " $Y$ " component of the IMF was mainly positive.

are the strongest we have observed from Kiruna. After about 14.15 U.T. there was a steady decrease of magnetic disturbance and westward wind speed.

The weather deteriorated after 19.30 U.T. so that the record after that time is no longer useful, and no further polar passes were taken by $D E-2$ during the event after orbit 7573.

\section{MODELLING THE THERMOSPHERIC RESPONSE TO LARGE POLAR ELECTRIC FIELDS AND AN EXPANDED AURORAL OVAL}

The polar electric field model of Heppner (1977), modified to correspond to the $D E-2$ VEFI data from orbit 1943 has been used with the UCL 3D-TD model. In Fig. 15 the $D E-2$ track for orbit 1943 is projected into geomagnetic coordinates and superimposed on a scaled-up model based on the Model "A" of Heppner
(1977). The scaling has been performed to generate a total cross-polar cap potential of about $150 \mathrm{kV}$ and to locate the major boundaries of the dusk and dawn parts of the auroral oval and the polar cap as observed on orbit 1943. We have not attempted to include in this large electric field (LEF) model details such as the distinct high velocity lower latitude border of the evening auroral oval which was observed on orbit 1943 by VEFI. The polar electric field (V2) described by Volland (1978), as an analytical equivalent of Heppner's model $\Lambda$, has been used for further simulations, for comparison with these "disturbed" simulations.

Modelling the ionospheric plasma densities for conditions appropriate to $12.00-18.00$ UT on 12 December 1981 and 10.00-18.00 U.T. on 17 December 1982 on a global scale is difficult at the present. Thermal plasma and energetic plasma data are available for the 


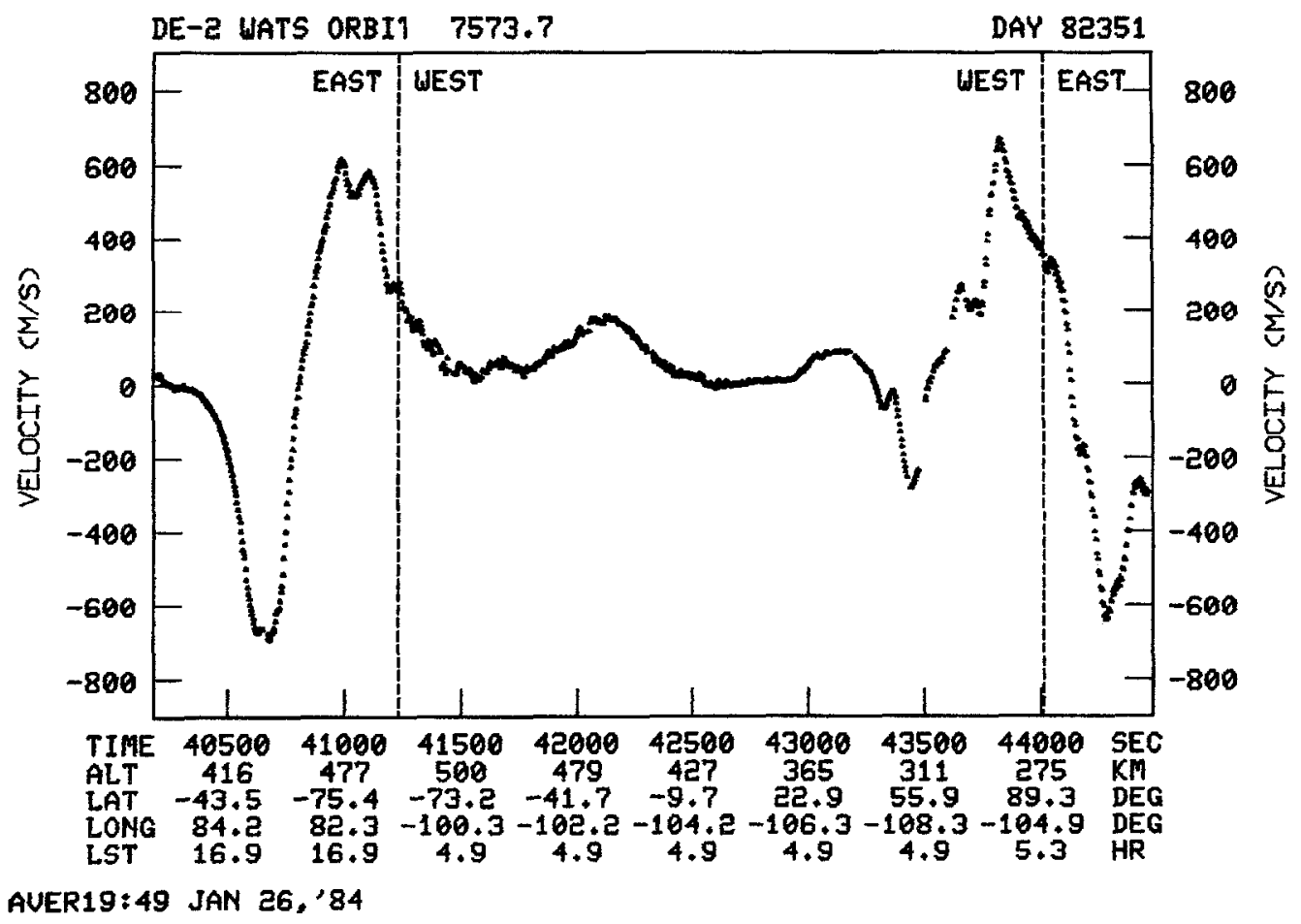

FIG. 12. THE DETAILED OBSER VATIONS OF THE ZONAL WIND FROM DE-2 MEASURED BY THE WATS INSTRUMENT FOR ORBIT 7573 (11.50 U.T. 17 DECEMBER 1982).

The dusk auroral oval was located on the right hand side of the diagram, where there was a single peak of the sunward winds, of $650 \mathrm{~s}^{-1}$, close to $73^{\circ}$ geographic latitude. The peak anti-sunward winds in the polar cap were also about $650 \mathrm{~m} \mathrm{~s}^{-1}$. The eastward winds of the dawn auroral oval were much weaker, about $300 \mathrm{~m} \mathrm{~s}^{-1}$ at this time, during the period when this geomagnetic disturbance was still increasing in magnitude. At this time the longitude of the satellite crossing of the dusk auroral oval was about $75^{\circ}$ East, and thus more than $1000 \mathrm{~km}$ East of Kiruna.

three Northern Hemisphere DE polar passes used in this study. However, these data fall far short of the global coverage required for the empirical or numerical modelling of the ionospheric plasma distribution over the entire polar region throughout the period of the disturbances as would be required to input a comprehensive high latitude plasma density model into the 3D-TD model.

Three ionospheric models will be used in the series of simulations to be compared with the dynamical observations.

\section{Ionospheric Model 1 (Chiu)}

The Chiu (1975) global ionospheric model has been used as an element of a number of global thermospheric models. At low and middle latitudes its response to seasonal, latitudinal, local time and solar activity variations has been shown to be of very considerable value. Its major disadvantages for thermospheric modelling are due to its lack of response to high-latitude geomagnetic activity, as has been discussed at some length by Fuller-Rowell and Rees (1981); FullerRowell et al.(1984); Quegan et al. (1982) and by Rees et al. (1983a). It is nevertheless a valuable global model, due to its inclusion of solar activity, seasonal, longitudinal, latitudinal and local time variations. The "Chiu" model has thus been adopted as "Model 1", and used for baseline simulations including any geomagnetic enhancements of the ionosphere.

\section{Ionospheric Model 2 (Sheffield)}

A self-consistent high latitude ionospheric model (Sheffield Model) has been developed for slightly disturbed geomagnetic conditions by iterating between the UCL 3D-TD model and a polar ionospheric model, so that the resulting thermosphere and ionosphere both reflect high latitude convection and magnetospheric precipitation and the effects of solar heating and ionisation (Quegan et al., 1982; Fuller-Rowell et al., 1984). Compared with the "Chiu" high latitude 


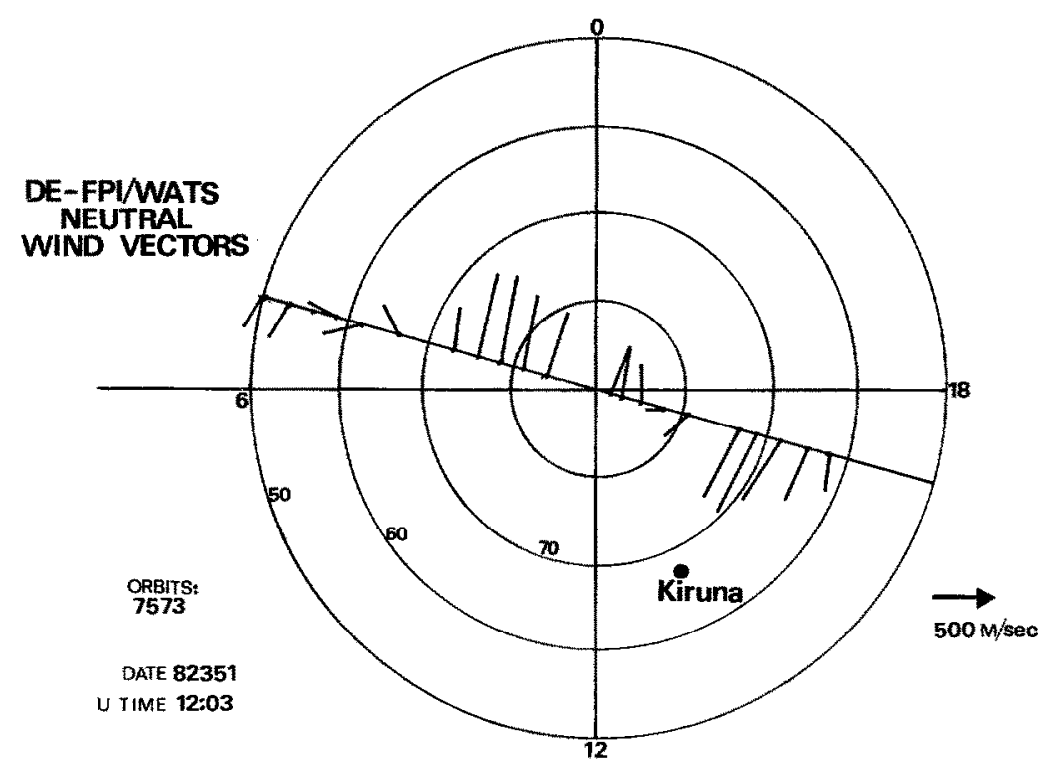

FIG. 13. NUUTRAL WIND VELOCTTY VECTORS MEASURED BY DE-2 COMBINING FPI AND WATS DATA FOR ORBIT 7573, ABOUT 11.50 U.T. ON 17 DECEMBER 1982, OVER THE NORTh POLE.

Maximum anti-sunward velocities in the polar cap (i.e. above about $80^{\circ}$ geographic latitude on the dusk side and above $60^{\circ}$ geographic on the dawn side in this plot) are about $750 \mathrm{~m} \mathrm{~s}^{-1}$. As for orbit 1944 , the auroral oval is expanded equatorward, so that the peak sunward velocities of the auroral oval are at about $65^{\circ}$ geomagnetic latitude. Unfortunately, VEFI electric field data are not available for this particular orbit, or for any time during this disturbed period of 17 December 1982.

ionosphere, plasma densities in the "Sheffield" model are significantly enhanced where either direct ionisation by magnetospheric precipitation or the convective transport of plasma are important. The dusk auroral oval is one region where both effects are important, and as a result, plasma densities in the middle and upper thermosphere are enhanced compared with those of the "Chiu" model for winter polar conditions, throughout the afternoon and evening parts of the auroral oval. The "Sheffield" polar ionosphere has been scaled geometrically to match the physical boundaries of the LEF polar electric field model. The model is thus no longer fully self-consistent, but is a considerable improvement over the lack of response of the "Chiu" model to precipitation. The "Sheffield" (adapted) model was intended to simulate the effects of very modest fluxes of cnergetic electrons (Quegan et al., 1982). Comparison with the fluxes published recently by Spiro et al. (1982) would indicate that the Sheffield model may underestimate the ionisation caused by enhanced precipitation associated with the major disturbances of 12 December 1981 and 17 December 1982, over most regions of the auroral oval and polar cap.

\section{Ionospheric model 3 (PIONS)}

The precipitating electron fluxes used in the "Sheffield" model are considerably lower than those characterizing the two disturbed periods under study (for example the values published by Spiro et al., 1982 for $A E>400$ ). The inadequacy of the "Sheffield" model to simulate even "average" geomagnetic conditions in the polar regions has already been noted by Rees et al. (1983a). A third ionospheric model has thus been generated adapting the results of the study of the ionospheric effects of auroral precipitation presented by Roble and Rees (1977). They computed the ionisation profiles caused by energetic electron precipitation of different characteristic energies and fluxes under both daytime and night-time conditions. Their (nearly asymptotic) values, for periods of the order of $1000 \mathrm{~s}$ after precipitation onset, have been adopted as indicative of the steady-state plasma density values. These results do not allow for the changes which occur in the neutral atmosphere itself, or for the effects of winds and convection in redistributing plasma or changing recombination coefficients (due to strong electric fields or neutral temperature or composition change). 


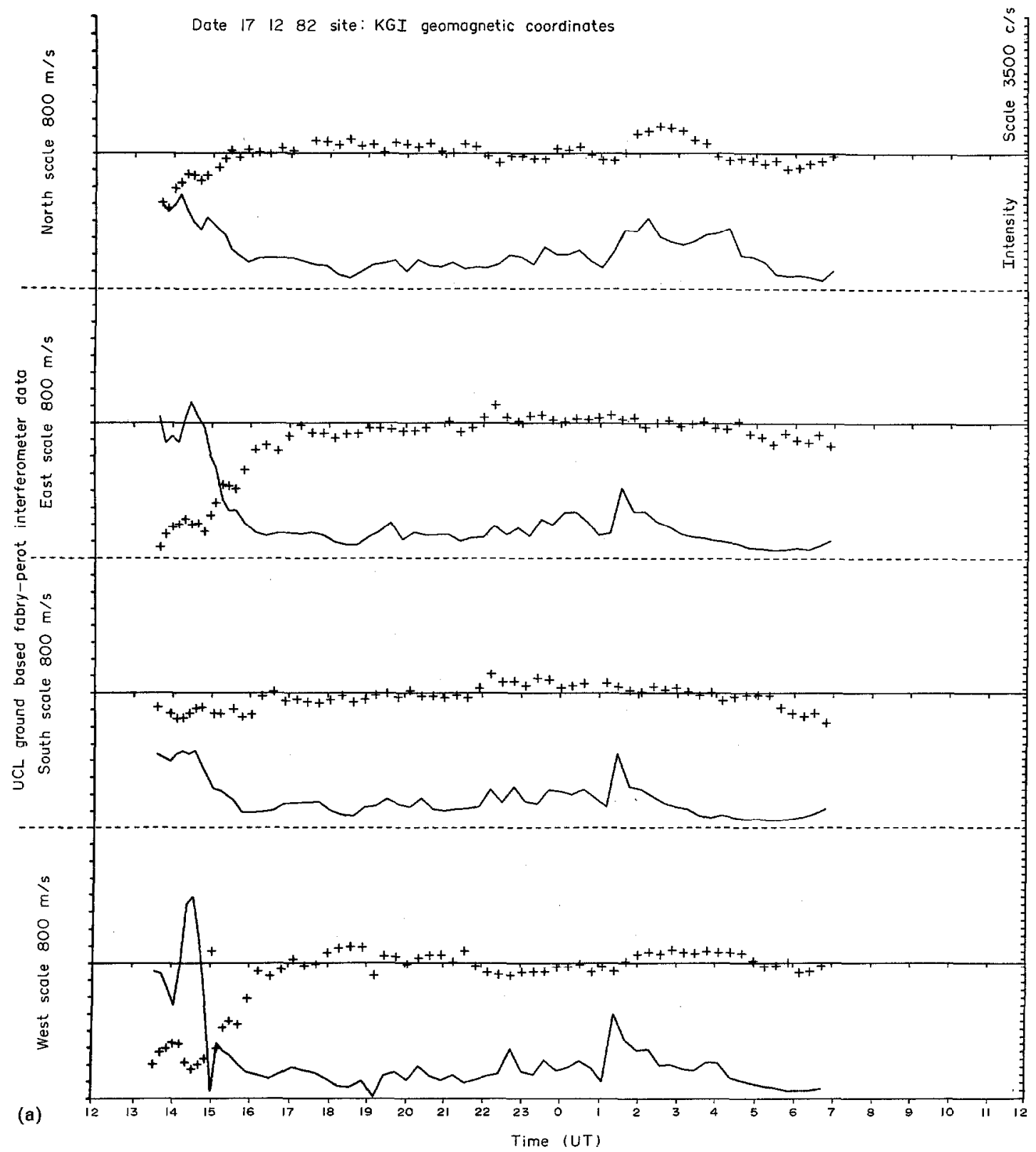

Fig. 14. Thermospheric WiNDS OBSERVATIONS FROM KiRUNa (KGI) ON 17 DECEMBER 1982.

Observations are shown for the seven separate viewing directions, presenting both wind velocity (crosses) and $630 \mathrm{~nm}$ intensity (solid line) for the hours of darkness. All except the zenith direction are observed at a zenith distance of $60^{\circ}$, and the velocities (except zenith) are the derived horizontal wind velocities, i.e. the line of sight velocity multiplied by sec $30^{\circ}(1.155)$.

14(a) SHOWS THE COMPONENTS AND INTENSITIES MEASURED TO THE NORTH, EAST, SOUTH AND WEST OF KIRUNA (ALL MEASURED RELATIVE TO THE GeOMAGNETIC NORTH AT KIRUNA, $12^{\circ} \mathrm{W}$ OF GEOGRAPHIC NORTH).

To use the results of Roble and Rees (1977) it is necessary to scale their plasma density values to correspond to the actual energetic electron precipitation in a given region. In this way, the local electron density can be related to the total energy and the mean energy of the precipitation. Below $200 \mathrm{~km}$ altitude, where recombination is rapid and horizontal transport of relatively minor importance, the electron density 


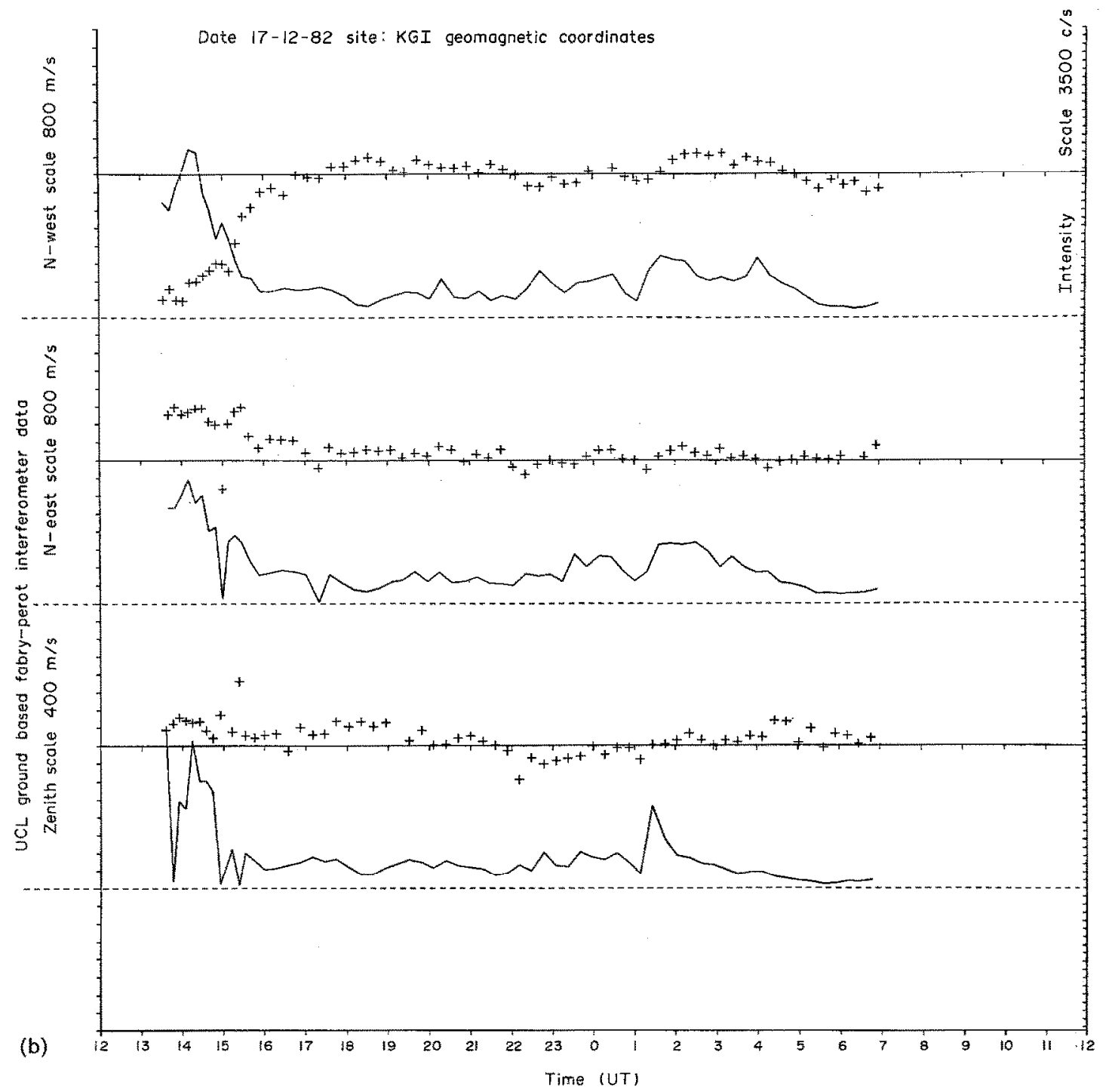

14(b) SHOWS THE WIND COMPONENTS AND 630 nm INTENSITUES MEASURED TO THE GEOMAGNETIC NORTH-WEST AND NORTH-EAST AND ALSO IN THE ZENTTH (THE LOCAL VERTICAL WIND).

The observations combine to describe a period of extremely high-speed westward and north westward winds between 13.50 and 17.00 U.1, with the highest velocities, at the start of observations, of close to $900 \mathrm{~m} \mathrm{~s}^{-1}$.

generated by a flux of electrons of a specific mean energy is calculated to be proportional to the square root of the ratio of the flux used in the 3D-TD model to that in Roble and Rees (1977) for the appropriate conditions. Above $300 \mathrm{~km}$, it might be considered that the plasma density should be a linear function of particle energy deposition. However, the plasma density data available shows that it is the scale height of the plasma density distribution which increases under conditions of intense precipitation, more than the peak densities. Pending treatment of the problem with a fully consistent coupled ionospheric and thermospheric model, the plasma densities in the upper thermosphere $(300-500 \mathrm{~km})$ have been constrained not to exceed by more than $50 \%$ the values of the Sheffield model. Between 200 and $300 \mathrm{~km}$, a linear merging is forced between the values below and above these respective limits. The consequent increases of plasma densities are 


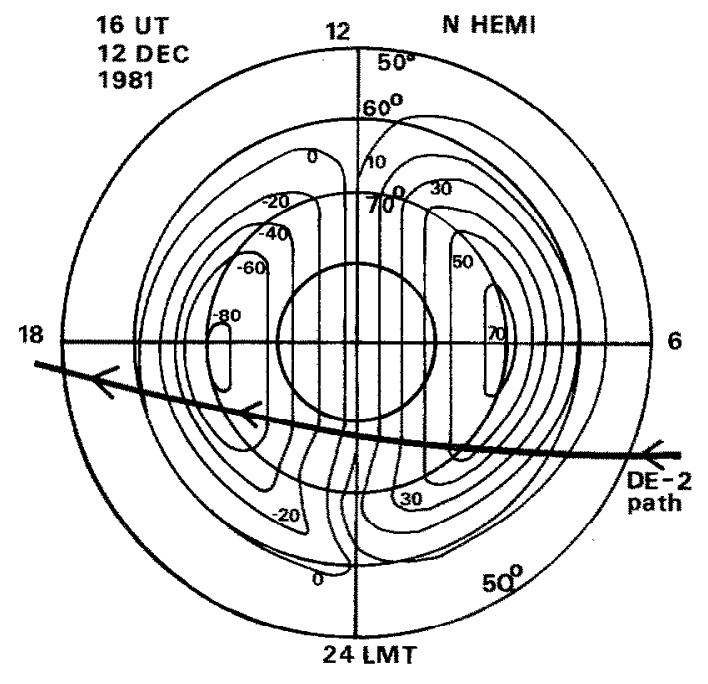

Fig. 15. Polar Electric Potential deRIVEd on the Basis of THE VEFI OBSERVATIONS DURING ORBIT 1943, ANO ASSUMING THLAT THE POTENTIAL DISTRIBUTION IS APPROXIMATELY SYMMETRIC AND WITH THE OVERALL CONFIGURATION DESCRIBED BY HEPPNER (1977) MODEL A.

The orbital path of $D E-2$ on (orbit 1943) is indicated, crossing the night side of the geomagnetic polar cap. This oblique crossing of the polar cap partly explains the smaller apparent potentials observed in the morning oval during this orbit compared with the evening auroral oval.

more consistent with the ionospheric currents, Joule heating and ion drag observed during disturbed conditions than are the values of the "Sheffield" model. This model is not self-consistent, and the horizontal and vertical transport of plasma by convection and winds will be among several sources of error. However, until fully self-consistent thermosphere/ionosphere models are perfected, the ad hoc "PIONS" model simulates the highly disturbed polar ionosphere significantly better than does the "Sheffield" model. The PIONS model is discussed in detail in Smith (1984).

Comparative values of the electron densities generated by these three semi-empirical or theoretical models are shown in Figs. 16, 17 and 18 respectively for an altitude of $320 \mathrm{~km}$. The relative enhancements of plasma densities for particular regions of the high latitude ionosphere can be judged from these figures. For the "Sheffield" model, plasma densities around the equatorial boundaries of the auroral oval and trough are merged with those generated by the "Chiu" model, while for the "PIONS" model, the computed ionisation calculated the "PIONS" code is added to the numbers generated by the appropriate "Chiu" model. The input conditions for the three ionospheric models are summarized in the Appendix. For the simulations of disturbed conditions, the relatively large fuxes of kilovolt and higher energy electrons in the PIONS MODEL code enhances plasma densities in the regions below about $150 \mathrm{~km}$ by more than an order of magnitude compared with the CHIU model values. In each of the Figs. 16, 17 and 18, the neutral wind circulation at $320 \mathrm{~km}$ altitude is also shown at the same Universal Time of 15.60 U.T.

One of the important factors which has not been discussed is the geometrical relationship of the ion convection pattern to the magnetospheric electron precipitation pattern. As yet there are few soundlybased studies of this relationship and, as a result, all of the plasma density models can be criticised. The relationships which have been used in this study are justified by the quantitative agreement found by Rees et al. (1983a) and Hays et al. (1984) in comparisons of the UCL 3-D T-D model with the averaged wind data obtained by the $D E-2$ FPI and WATS instruments, a comparison which utilized the "Sheffield" selfconsistent ionsopheric model. The boundaries which were used in this model are summarized in Table 1. The model used to describe magnetospheric electron precipitation is simplified, and it has been assumed that precipitation and convection boundaries are closely related. In the real world, this close alignment of regions of convection and precipitation may not always occur.

The wind vectors produced by the three ionisation models (Figs. 16, 17 and 18), indicate the relative changes caused by each of the three models. There is a major increase in wind velocity throughout the entire high latitude region, relative to the "Chiu" simulation, in both the "Sheffield" and the "PIONS" simulations. Approximately, the wind velocities are doubled. There is a slight increase of about $20 \%$ on average for the winds produccd by "PIONS" compared with those produced by "Sheffield" for the $320 \mathrm{~km}$ altitude shown here. While that difference is insignificant compared with the consequences of the broad assumptions which have been adopted, the real differences between these two models are very important below about $200 \mathrm{~km}$. At such levels, the "PIONS" ionosphere is considerably enhanced, and this causes the winds below $200 \mathrm{~km}$ to be much higher. Also, Joule and friction heating create significant thermal differences, so that temperatures in the upper polar thermosphere are about $100 \mathrm{~K}$ higher in the "PIONS" model.

\section{THE SIMULATIONS}

The three ionospheric models and the two polar electric field models have been combined to generate both steady-state (U.T. dependent only) and full timedependent simulations. The initial response of the 

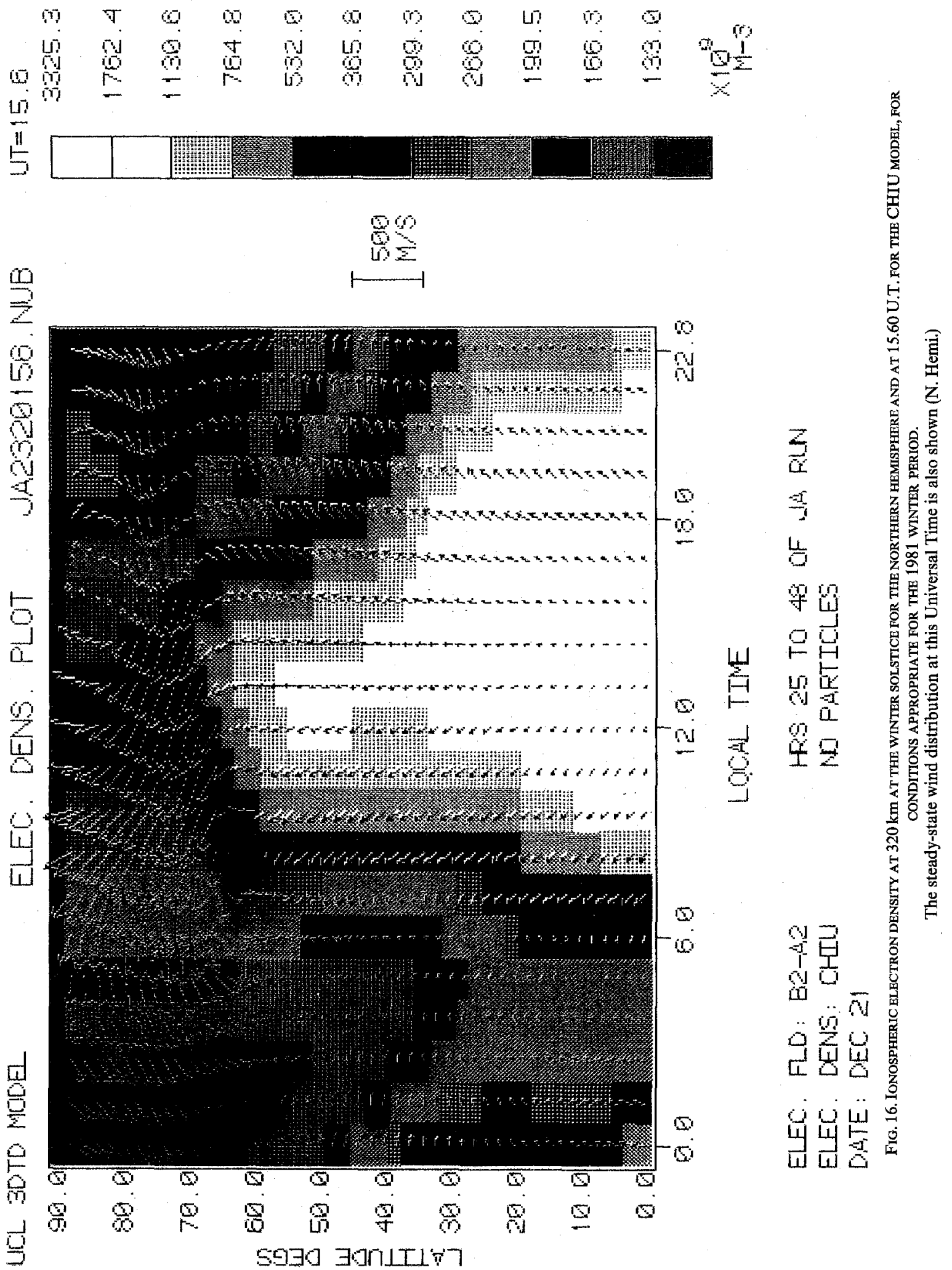

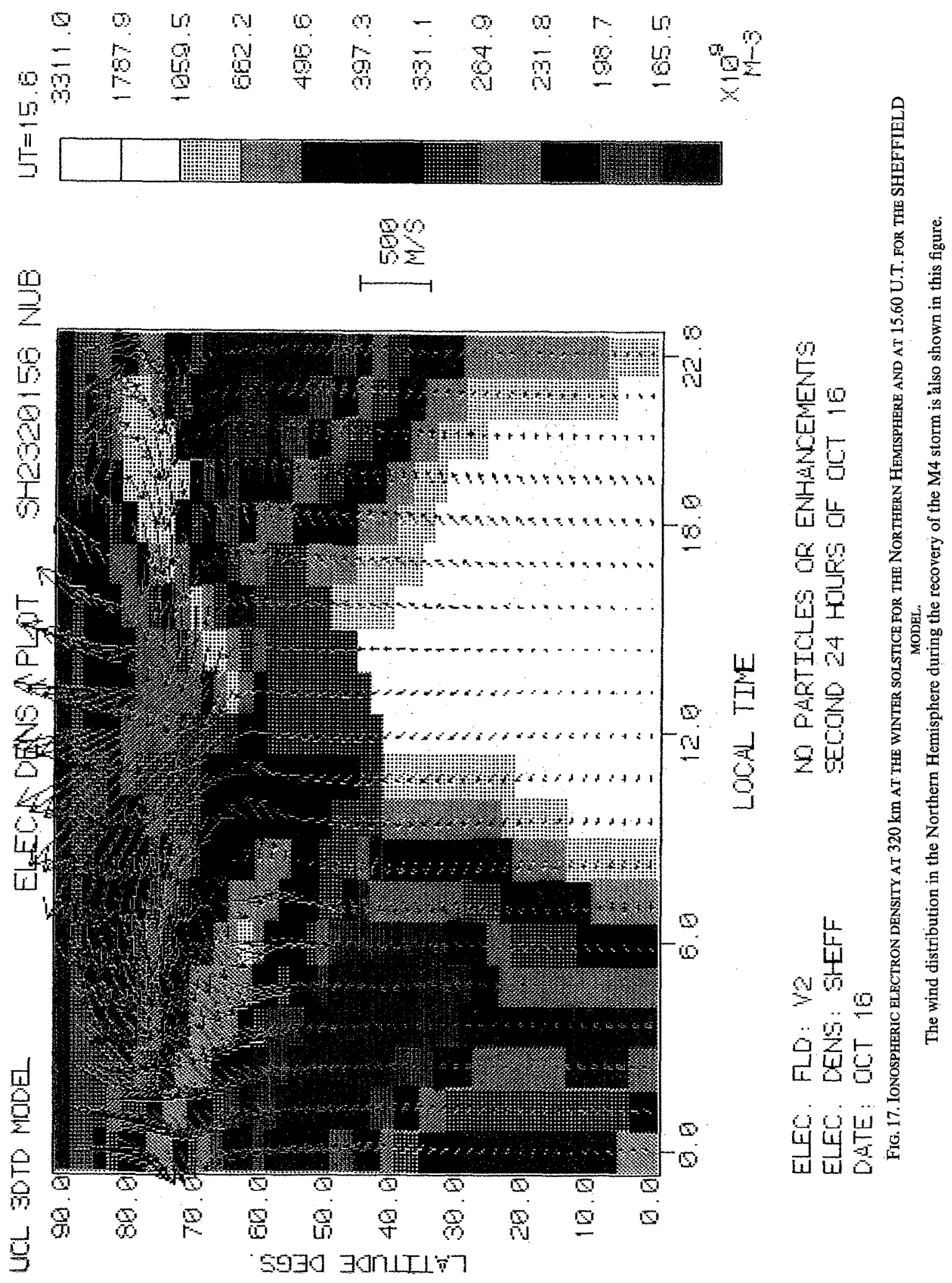


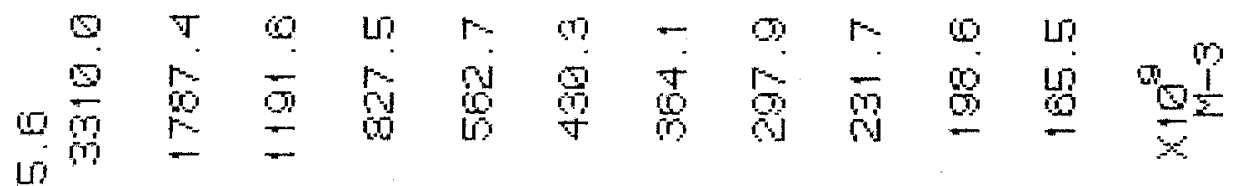
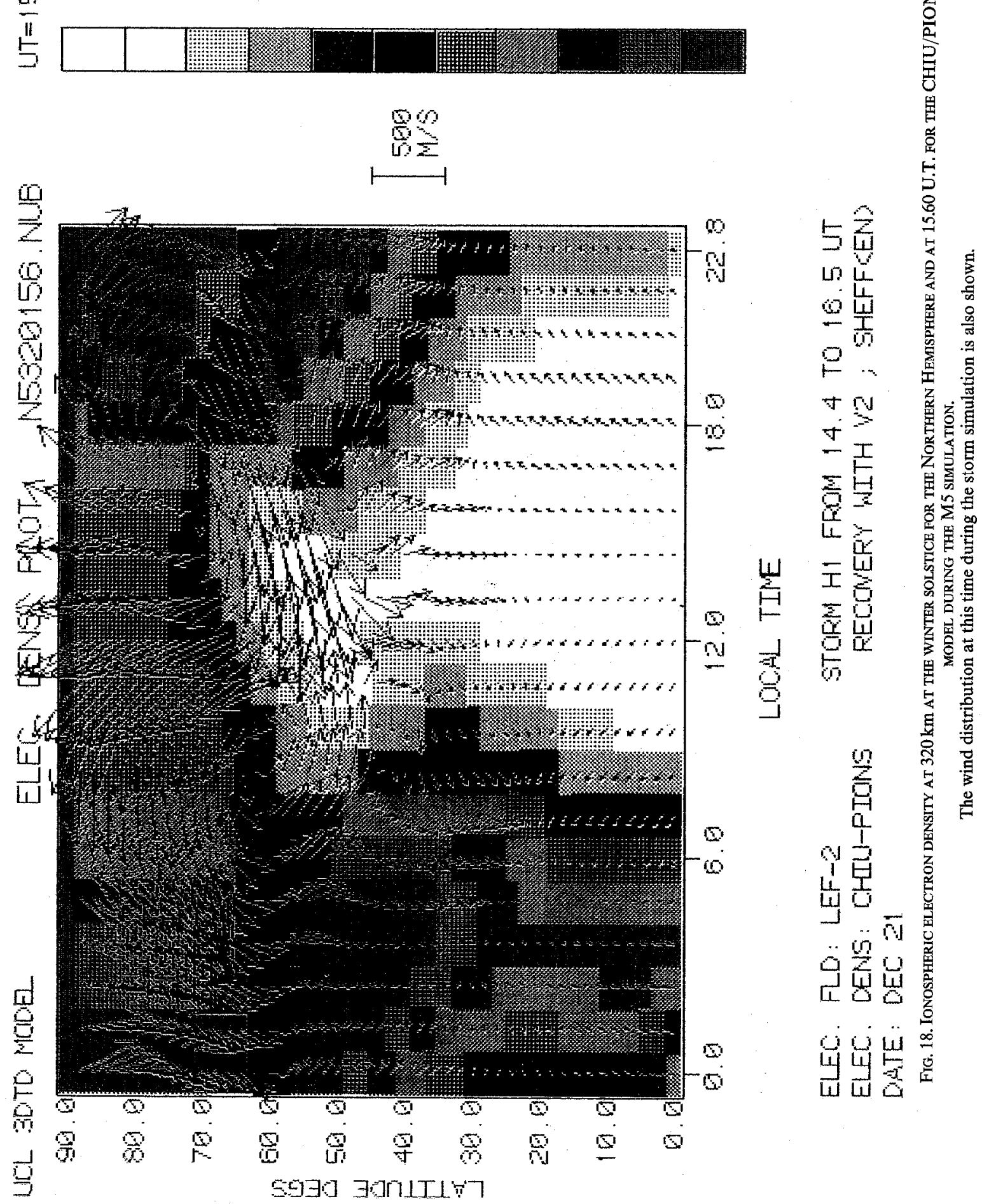

TABLE 1. ThE BOUNDARIES AND POTENTIALS OF THE HEPPNER "A" MODEL AND THE LEF POLAR ELECTRIC FIELD MODEL

\begin{tabular}{lcc}
\hline & The A field & The LEF field \\
\hline Geomagnetic conditions & $K_{P} \sim 3$ & Strong IMF, -ve $B_{z}$ \\
Cross-polar cap potential: & $76 \mathrm{kV}$ & $150 \mathrm{kV}$ \\
Potential of dusk boundary: & $-40 \mathrm{kV}$ & $-80 \mathrm{kV}$ \\
Potential of dawn boundary: & $36 \mathrm{kV}$ & $70 \mathrm{kV}$ \\
$\begin{array}{l}\text { Diameter of polar cap: } \\
\quad \text { (degrees geomagnetic latitude) }\end{array}$ & 32 & 40 \\
$\begin{array}{l}\text { Diameter of auroral oval: } \\
\text { (fastest sunward convection) }\end{array}$ & 42 & 65 \\
\hline
\end{tabular}

thermosphere to a large increase of geomagnetic input, as occurred around 12.00 U.T. on 12 December 1981 or around 08.00 U.T. on 17 December 1982, will be different from the steady-state response, since cnhanced back-pressures, etc., which take time to develop, will not be present at the start of a disturbance. The detailed thermospheric response will also depend on the Universal Time of the event, and the way in which the polar cap potential, polar cap size and magnetospheric precipitation all increase, from a relatively poorly described initial state, and later decay to another lower (but also poorly described) final state. Each of the global simulations are described in Table 2, and will be used as the basis for comparison with the satellite and groundbased data obtained during the two geophysical intervals.

There are three quasi-steady state simulations: Model M1 simulates moderately disturbed geomagnetic conditions and has been referred to as Model MD by Rees et al. (1983a).

The second model simulates the conditions of the strong disturbances of 12 December 1981 and 17 December 1982 by an increase in the size of the auroral oval and polar cap, and an increase in the cross-polar cap potential (LEF). There is no enhancement of the polar ionosphere above the "Chiu" model. There is no heating or ionisation by particle precipitation included in this model. Ion drag and friction heating are moderately strong in the upper thermosphere as a result of fast ion convection, but ion drag and friction (or Joule) heating below $200 \mathrm{~km}$ in the winter polar region are relatively small, due to low plasma densities.

In the third steady-state simulation (M3), the "Sheffield" polar ionosphere is used, thus introducing moderate sources of magnetospheric particles to enhance heating and ion drag in the upper thermosphere. Plasma densities, particularly in the region below about $200 \mathrm{~km}$, are certainly not sufficiently enhanced to correspond to the situations during the 12 December 1981 and 17 December 1982 events.
Three time-dependent simulations will also be used. The first (Model 4) is intended to match the 17 December 1982 event in general features such as the magnitude and location of the westward jet stream. In Model 4, it is assumed that the dominant geomagnetic input to the thermosphere is the increase in the size of the auroral oval and polar cap. This is associated with an increase in the cross-polar cap potential, and an increase in the energetic particle precipitation within the auroral oval and polar cap. The PIONS model is used to scale the ionospheric plasma density distribution to the particle inputs.

Model 4 corresponds to the empirical description derived here of the magnetospheric and thermospheric response to a prolonged period of strong southward IMF, and the simulation is tuned to the timedependence of the event of 17 December 1982. The disturbance input was started at 12.00 U.T. and was ended at 14.50 U.T.

Model 5 is similar to Model 4, in that the same (PIONS) plasma density model is used, and the same polar convection field is used. The simulation is, however, tuned to the event of 12 December 1981, by switching the disturbance on at a later time (U.T.), and reverting to a moderate level of geomagnetic input at a comparably later time (cf. the 17 December simulation). The disturbance input was started at 14.40 U.T. and was ended at 16.50 U.T.

The sixth simulation (M6) is similar to M2 and M3, but uses a slightly modified polar electric field, with a similar cross-polar cap potential to LEF-1. This polar field model (LEF-2) has a slightly greater equatorward expansion of the auroral oval and the regions of highest sunward ion convection. M6 also uses the SHEFFIELD polar plasma density model, scaled to the dimensions of the LEF-2 convection field boundaries. The polar ionosphere is thus not as well developed in this simulation as are the polar ionospheres used in the Model 4 and 5 simulations. The disturbance input was started at 13.20 U.T. and was ended at 16.20 U.T. 
5. COMPARISONS BETWEEN THE EXPERIMENTAL DATA AND THE RESULTS OF THE SIMULATIONS

\section{A. The satellite wind observations}

In Fig. 19, the $D E-2$ wind observations on orbits 1943,1944 and 7573 are compared with the winds generated by the three steady-state simulations. One of these simulations (M1) uses the V2 polar electric field model, and M2 and M3 use the LEF (large electric field) model.

Model 1 underestimates greatly the wind magnitudes observed in all three orbits, and places the sunward evening jet stream nearly $10^{\circ}$ too far poleward compared with the $D E-2$ data from orbits 1943 and 7573. Model 2 (LEF, Chiu) underestimates the observed wind magnitudes for orbits 1943 and 5753, in all regions, but correctly locates the westward wind jets for both events. Model 2 only slightly underestimates the sunward winds of the evening auroral oval for orbit 1944, but places the jet stream 5 degrees equatorward of its observed location.

Mode1 3(LEF, Sheffield) predicts well the magnitude and the location of the peak winds of the jet stream in the evening oval, for orbits 1943 and 7573 . This model (M3) slightly underestimates the anti-sunward winds of the evening side of the polar cap. Model 3 overestimates the magnitude of the sunward winds of orbit 1944 , and locates the jet-stream equatorward of the observed maximum

For orbits 1943 and 7573, Model 3 has the best overall correspondence to the satellite wind observations in all regions. This indicates that the polar electric field during the period around 12.00 U.T. on 17 December 1982 was qualitatively similar, in crosspolar cap potential and latitudinal extension, to that observed for orbit 1943.

In Fig. 20A, the satellite wind data for each of the three orbits are compared with the predictions of specific time-dependent simulations intended to investigate the dynamical response of the thermosphere to a time-dependent geomagnetic input. In these models, the polar electric field and the bigh latitude ionosphere bave been enhanced at the time of onset of the disturbances of 12 December 1981 and 17 December 1982, and the enhancements maintained for the duration (approximately) of the major geomagnetic disturbances (see Table 2).

The simulated wind structures corresponding to orbits 1943 and 7573 , representing times close to the

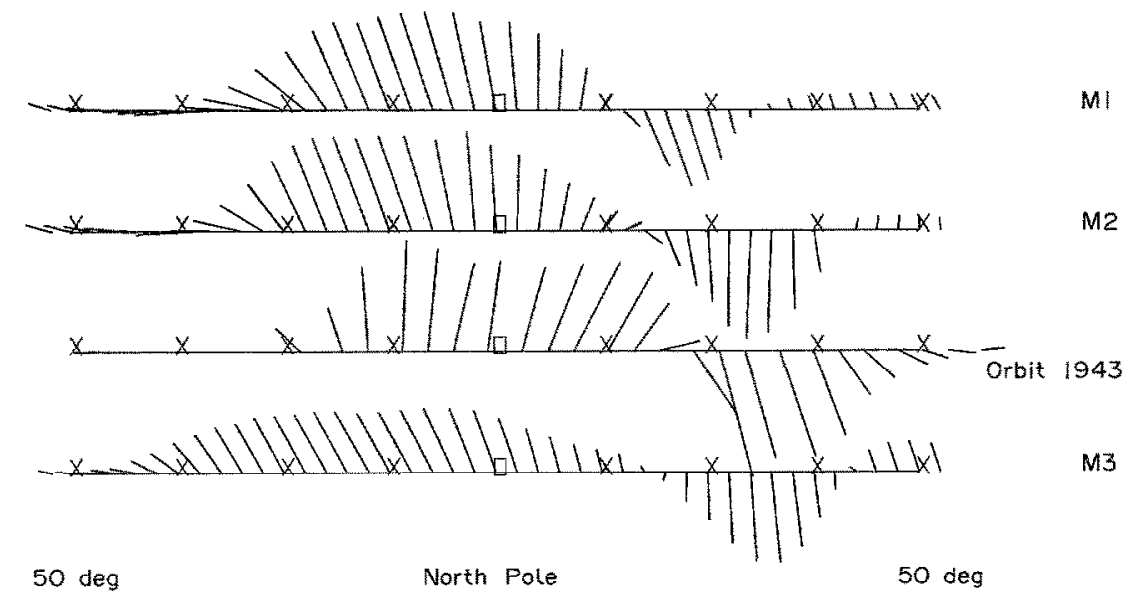

(a)

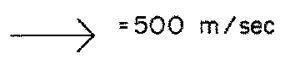

FIG. 19. COMPARISON OF THE DATA FROM ORBITS 1943, 1944 AND 7573 OF THE COMBINED FPI AND WATS VECTOR WINDS WITH THE APRROPRIATE SLICES TAKEN FROM THE STEADY-STATE SIMULATIONS ARE SHOWNIN FIGS. 19A, 19B AND 19C RESPECTIVELY.

IN 19(a) THE VECTOR WIND FROM ORBT 1943 IS COMPARED WTTH THE MODEL 1 SIMULATION (V2, SHEFFIELD), WHICH GENERATES A SUNWARD JET STREAM FAR POLEWARD OF THAT OBSERVED, AND OF APPROX. $60 \%$ OF THE OBSERVED VELOCITIES.

Model 2 (LEF-1, Chiu) locates the jet stream in the correct latitude range, and the wind magnitudes are comparable to those observed. Model 3 (LEF, Sheffield) successfully simulates both the location and the magnitude of the jet stream in the dusk oval, but is noticeably less successful than Model 2 in generating the observed fast anti-sunward winds in the polar cap. 


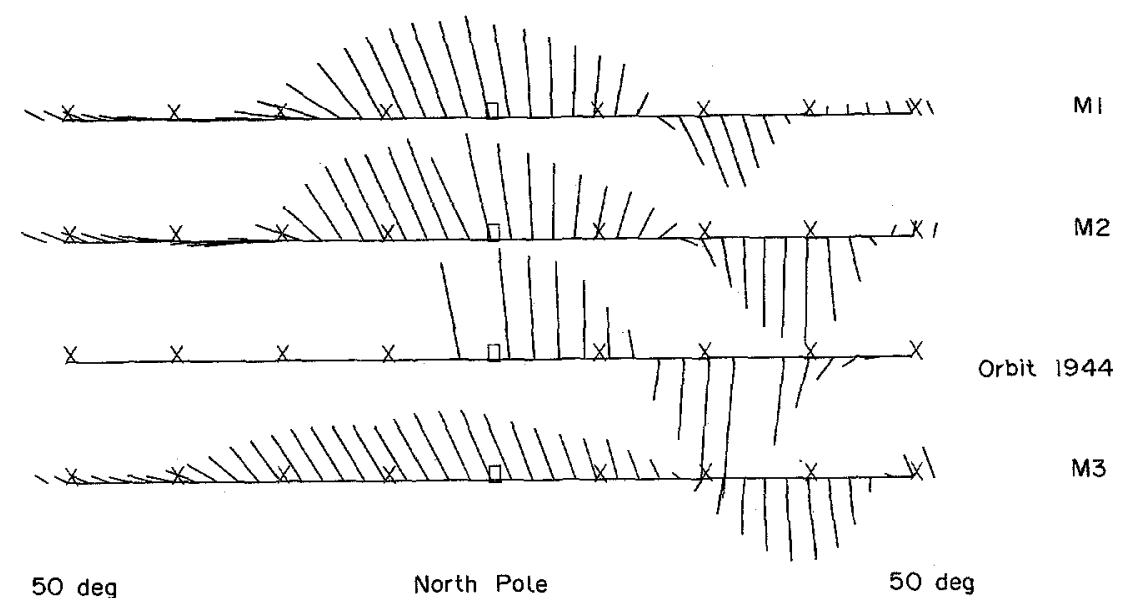

(b)

$$
\longrightarrow=500 \mathrm{~m} / \mathrm{sec}
$$

IN FIG. 19(b) THE M2 AND M3 MODELS PRODUCE WIND MAGNTIUDES WHICH ARE VERY CLOSE TO THOSE OBSERVED (ORBIT 1944). HOWEVER, THE USE OF A CONSTANT LARGE POLAR ELECTRIC FIELD IS SHOWN TO BE INAPPROPRIATE, SINCE THE REGION OF MAXIMUM WESTWARD WINDS IN THE DUSK AURORAL OVAL HAS CLEARLY MIGRATED POLEWARD SINCE THE PRECEDING ORBIT.

This is confirmed by the VEFI electric field data, which shows a comparable poleward migration of the region of strong sunward convection.

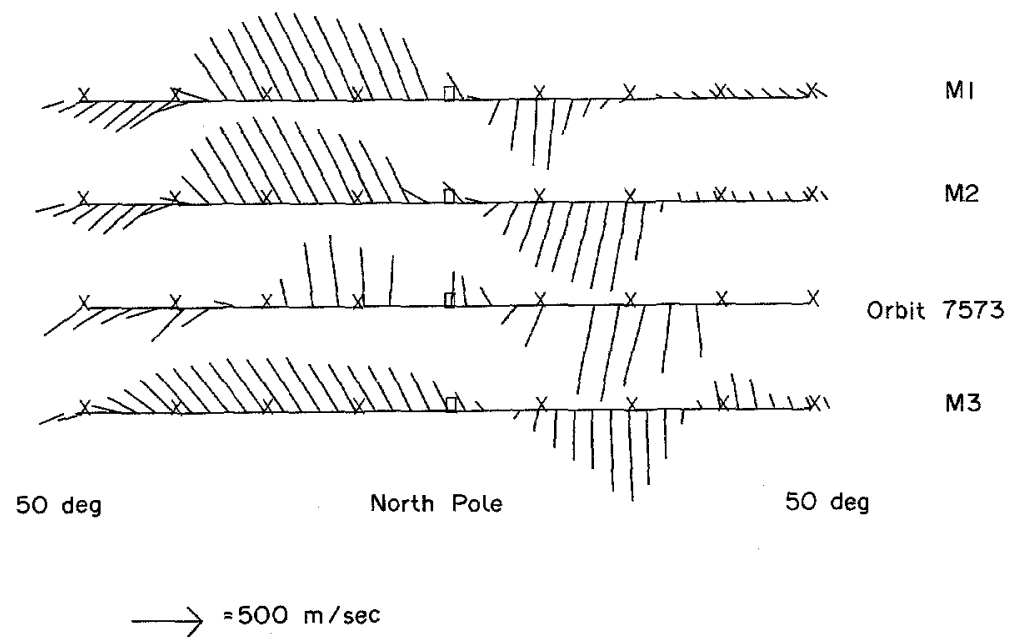

(c)

$* \operatorname{Sun} *$

IN Fig. 19(c) THE SAME COMPARISON IS SHOWN FOR ORBIT 7573. AT THE TIME OF THS ORBIT, THE M2 AND M3 MODELS CORRECTLY LOCATE THE WESTWARD JET STREAM, BUT THE MODELLED POLAR CAP WINDS ARE NOT IN SUCH GOOD AGREEMEN'I AS OBTAINED IN THE OTHER CASE STUDY WHEN VEFI DATA WAS AVAILABLE.

The ground-based magnetic data suggests that at the time of orbit 7375 , the auroral oval is expanding and the electrojet intensifying rapidly. In such a case, the polar cap winds may lag behind the auroral oval winds in their acceleration. 

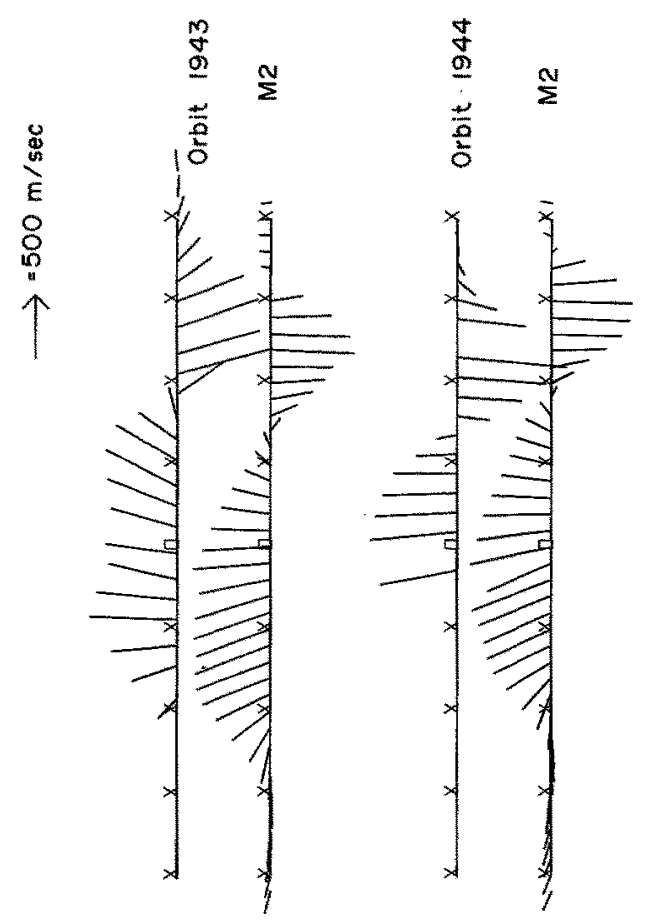

$\stackrel{n}{R}$
$\stackrel{n}{0}$
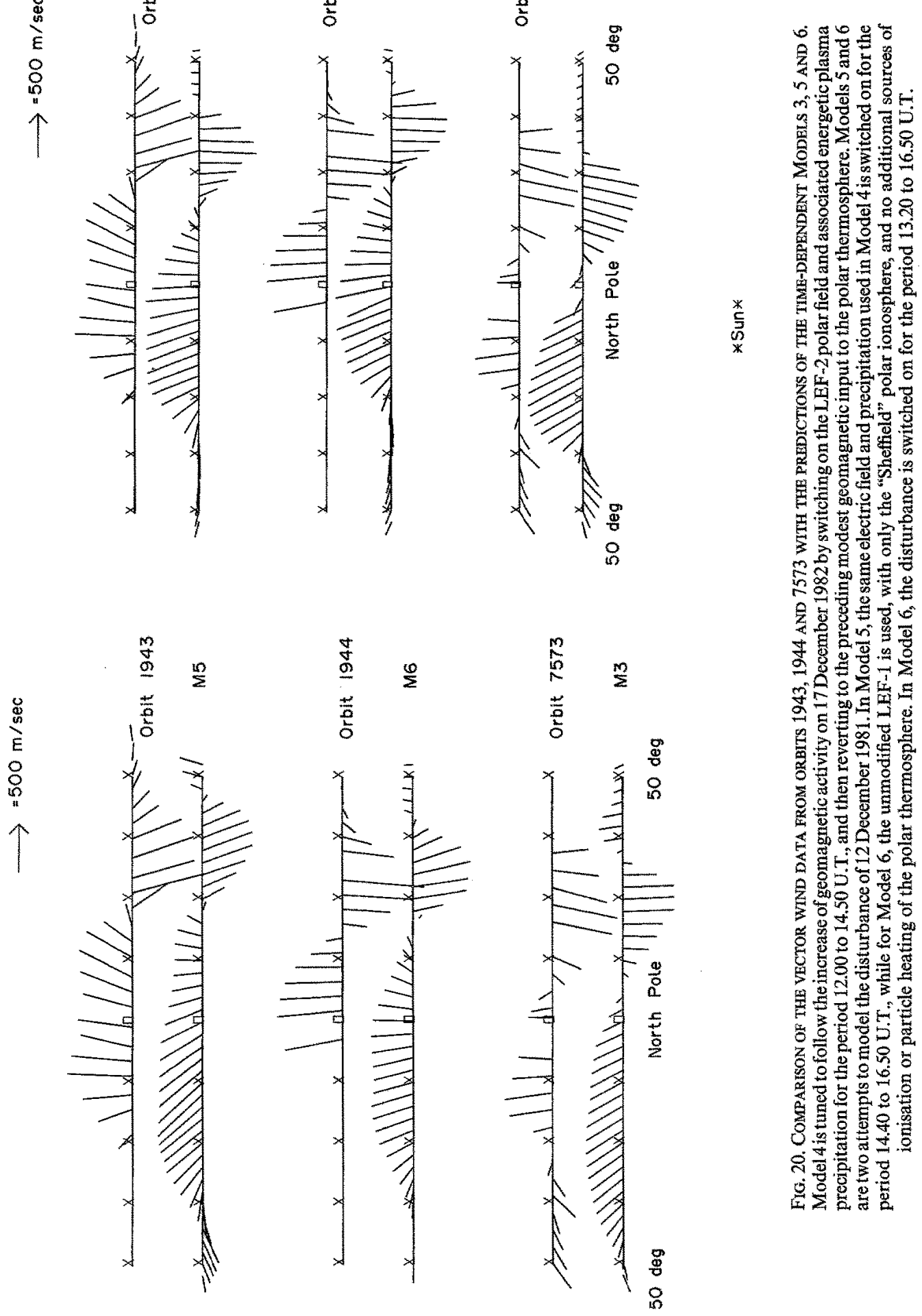
The westward thermospheric jet-stream of the evening auroral oval

TABLE 2. SUMMARIES OF THE INPUT CONDITIONS OF THE SIX THERMOSPHERIC MODELS

\begin{tabular}{lccc}
\hline & Polar ionosphere & Polar electric field & Condition \\
\hline Model 1. & Sheffield & A (V2) $(X X)$ & Steady-state \\
Model 2 & Chin & LEF1 & Steady-state \\
Model 3 & Sheffield & LEF2 & Steady-state \\
Model 4 & PIONS & LEF2 $(X X)$ & Time-dependent \\
Model 5 & PIONS & LEF-2 $(X X)$ & Time-dependent \\
Model 6 & Sheffield & LEF-2 & Time-dependent \\
\hline
\end{tabular}

(XX) Additional energetic particle precipitation/heating.

maximum extent of these disturbances, are in quite good agreement with the general features observed, with the possible exception that the anti-sunward winds of the polar cap are underestimated. For orbit 1944, the M6 simulation illustrates that the recovery from the earlier disturbance is an essential part of the explanation of the observed wind structures.

In Fig. 20B, these three orbits have been contrasted with the M2 model. This steady-state model provides acceptable agreement with orbits 1943 and 7573 (near peak disturbance times), but places the jet-stream 8 degrees equatorward of the observed location for orbit 1944.

The large wind magnitudes observed during orbit 1944 in the westward jetstream thus reflect the intense nature of the preceding disturbance, while the poleward retreat of the sunward jet stream shows a very rapid response to the contraction of the auroral oval between orbits 1943 and 1944 (approx. $100 \mathrm{~min}$ ).

In these simulations, the major objective has been to examine the response of the westward jet stream of the evening auroral oval. It can be noted throughout Figs. 19 and 20 that wind structures in the polar cap are complex but that, in general, the simulated winds are directed somewhat anticlockwise of the observed winds, although the overall antisunward wind speeds are of the correct magnitude $\left(600-800 \mathrm{~m} \mathrm{~s}^{-1}\right)$. The direction of the antisunward wind over the polar cap, and the existence of jets on the dusk or dawn boundaries of the polar cap may be due to asymmetric polar convection fields induced by systematic trends of the "Y" component of the IMF (Heppner and Maynard, 1983).

Indeed, the effect of such trends on winds in the polar and auroral regions has been examined by Rees et al. (1985b) and found to explain certain strong wind asymmetries. For the events of 12 December 1981 and 17 December 1982, however, the " $Y$ " component of the IMF was not consistent for periods of many hours, as in the cases examined by Rees et al. (1985b). The strong antisunward winds on the dusk boundary of the polar cap during orbit 1943 may reflect the existing negative " $Y$ " component of the IMF, however, all of the polar convection fields used in the simulations have been symmetric, thus reflecting no particular trend of the IMF' " $Y$ " component.

\section{B. The ground-based wind observations}

In Fig. 21, the zonal winds observed with the FPI located at Kiruna, Sweden on 12 December 1981 and 17 December 1982 are compared with those generated within several of the Model simulations. The predicted zonal winds of Model 1 correspond in direction before 18.00 U.T., but are of much smaller magnitude than the observed zonal winds (12 December). In this simulation, the auroral oval and its region of strong sunward ion convection is poleward of Kiruna in the afternoon period. The convection ion velocities arealso too low in this simulation. After about 20.00 U.T. (12 December 1981), the observed zonal winds and those predicted by Modcl 1 are in closer agreement.

Model 6 is tuned to the time-dependence of the disturbance of 12 December 1981, and the peak sunward winds match the observed thermospheric wind response quite well in magnitude and time variation before 18.00 U.T., when the simulation ended.

Model 4 and Model 5 simulate the respective timedependences of 17 December 1982 and 12 December 1981. The M4 Model represents the observed time dependence of the 17 December event quite well, however, although the M5 Model follows the timedependence of the 12 December event, the predicted wind magnitudes are rather too low.

The rapid recovery of the observed winds at the end of the geomagnetic disturbances of 12 December 1981 and 17 December 1982 has been crudely approximated in the simulations (M5, M6 and M4 respectively) by the decrease in the polar electric field from that of the LEF model $(150 \mathrm{kV})$ to that of the V2 model $(80 \mathrm{kV})$. The 


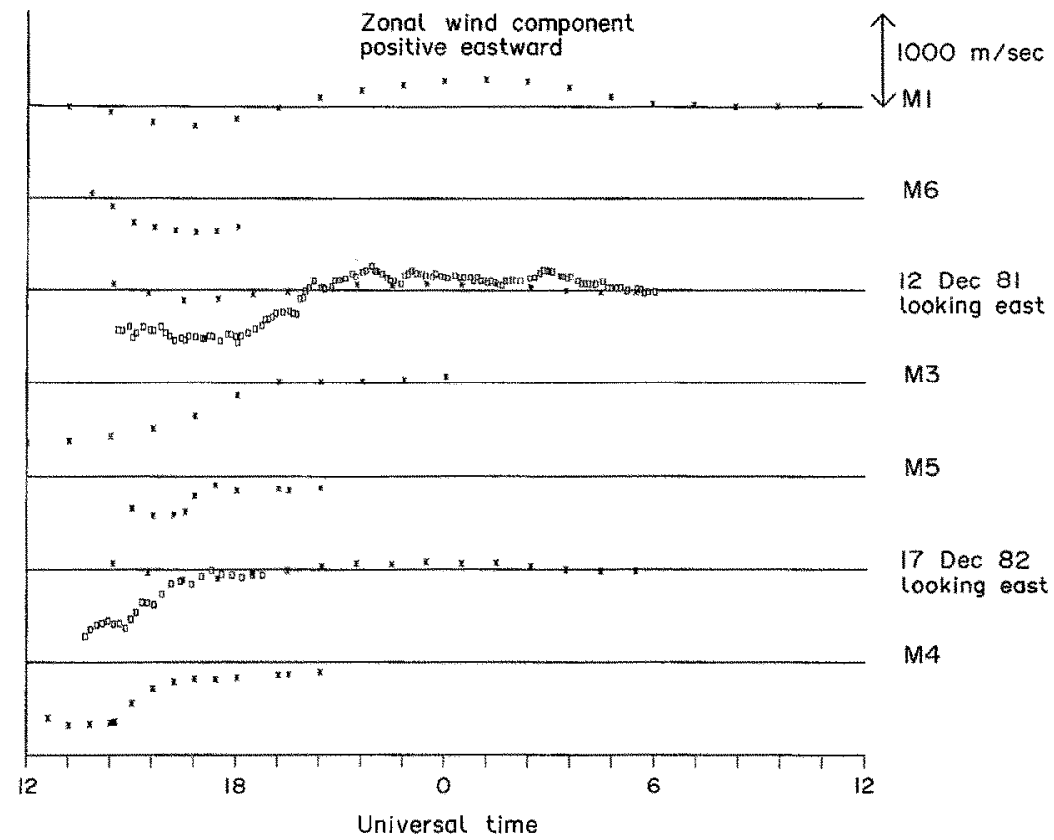

(a)

12 Dec 81

looking east

M3

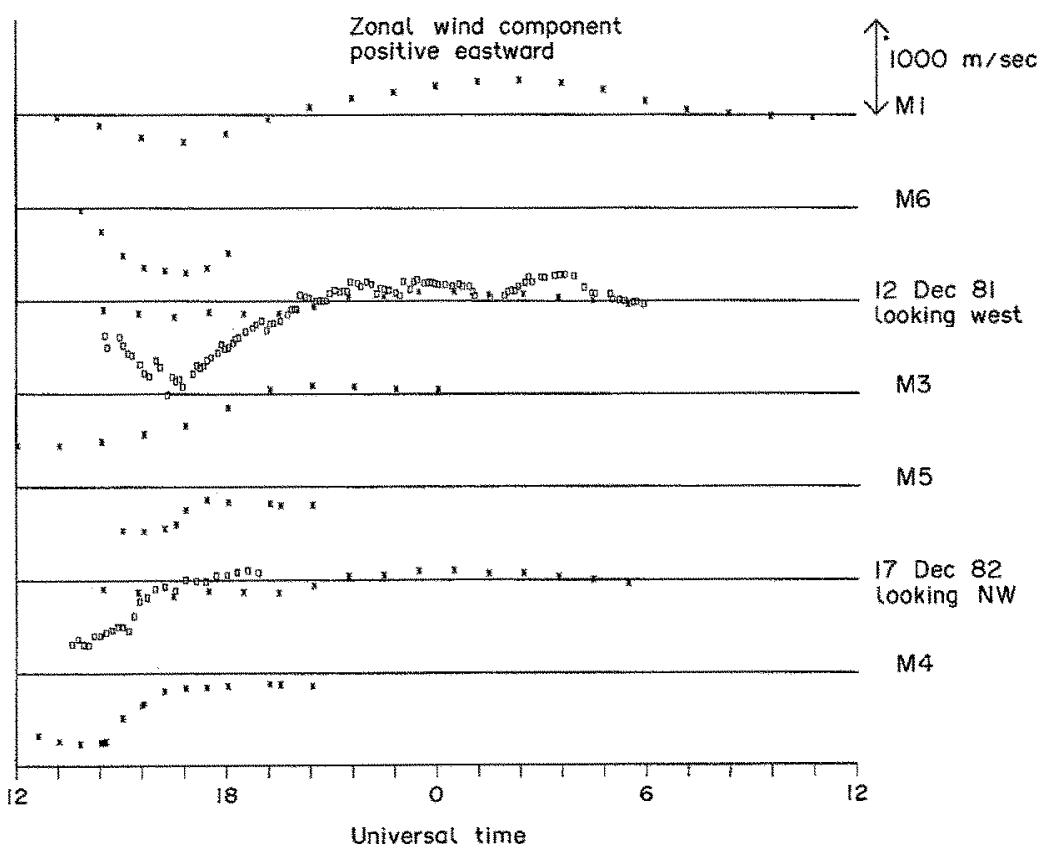

Fig. 21. COMPARISON OF THE ZONAL WIND OBSERVATIONS FROM THE GROUND-BASED INTERFEROMETER AT KIRUNA ON 12 DECEMBER 1981 AND 17 DECEMBER 1982 WTTH THE PREDICTIONS OF THE MODEL. STMULATIONS, AND THE MBAN WiNDS OBTained From KrRUNA FOR THE MONTH OF DECEMRER 1981.

Models 1,2 and 3 are "steady-state", and the variations which are seen are mainly due to the Earth's rotation carrying the observing station beneath a quasi-stationary wind pattern. For Models 4, 5 and 6 , the temporal evolution of the global wind pattern in response to changing geomagnetic energy input is a major factor in the observed dependence of the winds. The evolution of the GB FPI wind data during both periods can only be explained by the temporal evolution of the polar electric field and geomagnetic energy input. The winds observed in the afternoon periods during both events are far larger than the "mean" winds, which are also smaller in value than the least disturbed model shown here.

The mean zonal winds observed from Kiruna for the month of December 1981 are shown in comparison with the data for 12 December 1981 and 17 December 1982, as indicated by the crosses in the same panels as the 12 December and 17 December data. 
success of these simulations in predicting the rapid reduction of wind speeds observed at the end of both events shows that the rapid decrease in wind speed is the natural dynamical response of the thermosphere to the reduction of magnetospheric momentum forcing (ion drag), as the auroral oval contracts and the cross-polar cap potential decreases. The wind decrease is not merely the evolution of the thermospheric circulation at Kiruna with Universal Time, depicted in the steadystate models.

In Fig. 21, the average zonal winds observed from Kiruna for 17 days in December 1981 are also shown, and compared with the data of 12 December 1981 and 17 December 1982 . These average winds are about $50 \%$ of the M1 model (itself a model corresponding to relatively disturbed geomagnetic conditions), and are far less than the zonal winds observed during the two major disturbances.

In Fig. 22, a similar comparison is carried out for the meridional wind components. All the models predict the low meridional wind speeds of the afternoon period. Model M3 overestimates the winds observed after 18.00 U.T. by a factor of about $20 \%$, while M1 (which uses the more average V2 polar field and an enhanced ionosphere) matches the equatorward velocities after 17.00 U.T. rather well. In the steady-state conditions, the strong zonal, anti-sunward winds observed over the polar cap on orbits 1943 and 7573 would map into strong equatorward winds of the night-time auroral oval as depicted by the $\mathrm{M} 2$ and $\mathrm{M} 3$ simulations. These winds did not persist between the time of the 1943/1944 orbits (16.00-17.00 U.T.) and 20.00-22.00 U.T. when Kiruna came under the influence of the anti-sunward polar cap winds on 12 December 1981, indicating again the rapid deceleration of the wind system in the polar thermosphere once the strong momentum source is removed.

Comparably strong, and in some cases much stronger, equatorward winds have, however, been observed in the night-time auroral oval on other occassions (Hernandez and Roble, 1982; Rees et al., 1982). It would appear, from the evidence of the satellite and ground-based wind data, that the dynamical relaxation of the thermosphere after intense momentum forcing occurs in a time period of the order of $2-3 \mathrm{~h}$ only. This is in agreement with the predictions of the theoretical 3D-TD model.

The average meridional winds observed from Kiruna during December 1981 are also shown in Fig. 22. As might be expected, they are, as with the average zonal winds, significantly smaller than the predictions of all of the models during the period between 18.00 and 05.00 U.T., and barely exceed $60 \%$ of the observed meridional winds of 12 December 1981.

\section{DISCUSSION}

By combining the ground-based and satellite thermospheric wind measurements of two instances of extreme sunward thermospheric jet-streams occurring in the evening auroral oval, it has been possible to assess the geophysical mechanisms involved in generating these extreme winds, and to identify the necessary preconditions for such disturbances to occur. It has also been possible to investigate the state of the Interplanetary Magnetic Field which can generate these relatively rare events.

Ion drag coupling of momentum from ions, driven by convective electric fields, into the neutral atmosphere is the principle physical mechanism by which extreme jet streams are generated.

In addition, there appcar to be three necessary and apparently sufficient preconditions for the generation of the extreme jet-streams. Firstly, the auroral oval must be expanded equatorward, at least doubling the area of the polar cap. Secondly, the magnitude of the cross-polar cap electric potential has to increase more than proportionally to the dimensional increase of the polar cap, in order to drive average (rather than peak) ion velocities within the dusk auroral oval in excess of 1 $\mathrm{km} \mathrm{s}^{-1}$; Thirdly, a combination of magnetospheric energetic electron precipitation and processes resulting from the rapid convection must act to raise the average ionospheric plasma densities throughout the middle and upper thermosphere considerably above the levels predicted by the "Chiu" ionospheric model for the evening auroral oval region at the winter solstice period (i.e. a non-sunlit region).

Increasing only two of these parameters will not provide the magnitude or geographical (or geomagnetic) distribution of high velocity winds as observed during either of these two spectacular events. It may be inferred that the ionospheric plasma density enhancement affects a much wider region than that of the dusk auroral oval.

Given this combination of circumstances, extreme wind magnitudes will be generated within the dusk auroral oval, in regions where the eastward electrojet is intense. When such winds are generated, it is possible that the region of intense flow will reach to unusually low geomagnetic latitudes. Meriwether et al. (1985) have reported a similar event observed from Calgary, Canada (GM lat 60N).

At the root of such events is undoubtedly the combination of a strong total IMF and a large southward component. The large value of the IMF is essential to compress the Earth's magnetosphere, and thus expand the auroral oval. In these two events, the southward turning of the IMF can be directly related to 


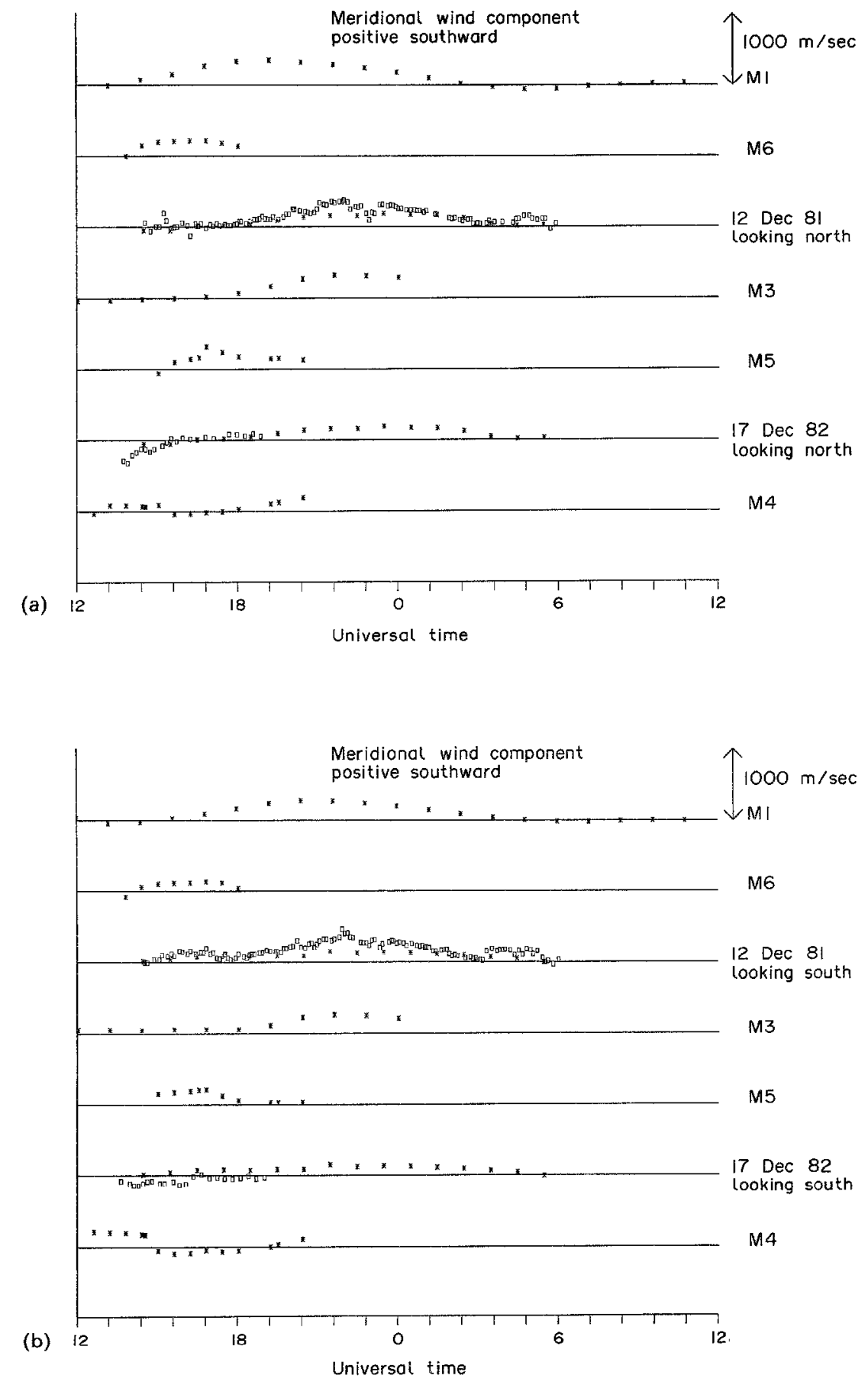

FIG. 22. COMPARISON OF THE MERIDIONAL WLND OBSEKV VATIONS FKOM THE GROUND-BASED INTERFEROMETER AT KIRUNA ON 12 DECEMBER 1981 AND 17 DECEMBER 1982 WITH THE PREDICTIONS OF THE SIX MODEL SIMULATIONS (AS FOR FIG. 21).

The mean meridional winds for the month of December 1981 are shown in comparison with the data for 12 December 1981 and 17 December 1982 by the crosses in the same panels as the 12 December and 17 December data. 
the onset of the period of generation of extreme westward winds. Conversely, the nortbward turning of the IMF appears to signal the immediate end of the period of generation of the extreme winds (although the previously generated winds may persist for the order of $2 \mathrm{~b}$ ). The role of the " $Y$ " component of the IMF is unclear, since both polarities are represented.

A large IMF alone (i.e. after 18.00 U.T. on 17 December 1982) is not a sufficient condition for the generation or maintenance of the extreme sunward jet stream. It can be concluded that these events are driven in a direct manner by momentum and energy transfer from the solar wind, and only when there is a large value of the IMF $(>10 \mathrm{nT})$ with a strong southward component $(>5 \mathrm{nT})$.

Most events of this nature are inherently non steadystate. Firstly, the peak values of solar wind and magnetosphere energy and momentum coupling, which are essential to drive such extreme events, appear to be maintained only for periods of a few hours. A reduction in the total magnitude of the IMF, or a northward turning of the meridional component, will terminate the "directly driven" phase. As a result, the rate of evolution of the convection electric field, and thus the rate at which input of magnetospheric energy and momentum to the thermosphere changes, is usually more rapid than the capacity of the thermosphere as a whole to reach equilibrium in response to the energy and momentum forcing. It is important to determine the relationship of these rare events to recognised geomagnetic phenomena. The 12 December 1981 event only registered $K_{p}=5$, despite the strong positive magnetic bays in the afternoon sector of the auroral oval. Presumably, no strong substorm events were occurring in the midnight region of the auroral oval throughout this period, that, by generating extreme enhancements of Hall conductivity, would have generated negative magnetic disturbances commensurate with the 450 nT positive disturbance observed in the northern Scandinavia region. The magnitude of this positive bay would, conventionally, have scaled to a negative bay (substorm) in excess of $1000 \mathrm{nT}$. On the basis of $1000 \mathrm{nT}$ magnetic disturbances, $K$, should have registered about 7 . The 17 December 1982 event ( +850 nT in Scandinavia) might have been expected to scale to negative (substorm) magnetic disturbances of the order of $2000 \mathrm{nT}$, and this is consistent with the observed $K_{p}$ value of 7 .

It has not been possible to carry out, within the confines of this study, a statistical analysis of those large geomagnetic disturbances which have generated a strong positive bay disturbance, as opposed to those which, for the same or greater level of geomagnetic activity, do not. Indeed, this pre-supposes that most or all of the very large positive bays which are observed (say above $400 \mathrm{nT}$ ) are associated with the appropriate geophysical conditions (large expanded auroral oval, large cross-cap potential) to generate the extreme westward winds.

The class of events of which we have described two in detail are rare, even at the time of high geomagnetic activity, such as the recent period 1979-1983, Routine observations with a ground-based Fabry-Perot interferometer at Kiruna have been carried out since the $1980 / 1981$ winter on a total of some 400 clear nights. Only the two events described have reached magnitudes of the order of $800-900 \mathrm{~m} \mathrm{~s}^{-1}$, with another six events reaching 500 to $600 \mathrm{~m} \mathrm{~s}^{-1}$. The period of the year in which the afternoon auroral oval can be well observed from Kiruna is from late October to early March. Another event in October 1981 was reported by Meriwether et al. (1985), and a survey of magnetic data from KGI (Kiruna, Sweden) has indicated a maximum event frequency of the order of one per month in periods of high geomagnetic activity. About $60 \%$ of such events will not be obseryable from the ground due to weather, etc.

This rate of occurrence is considerably less than the frequency of occurrence of periods where $K_{p}$ was greater than 6, a higher level of geomagnetic activity than that indicated for the 12 December 1981 event. It may be concluded that conventional indicators of geomagnetic activity such as $K_{p} A_{p}$, and $A E$ which are based on ground-based magnetic records are not a particularly valuable indicator of extreme sunward thermospheric jet-streams in the evening auroral oval.

One aspect which must be discussed is the correspondence between observations of such events by a ground-based FPI, as opposed to observation from a space-borne in situ instrument such as WATS. The GBFPI measures the beight-integrated thermospheric wind along a slant path through which, during large disturbances observed in the auroral regions, the plasma densities are probably strongly enhanced, as are the volume emission rates of the $630 \mathrm{~nm}$ OI emission. The mean height region to be associated with the GBFPI wind observation is not immediately determinable from the ground-based data itself, but it may be quite different from the $240-280 \mathrm{~km}$ often associated with the OI $630 \mathrm{~nm}$ emission. During major auroral events, it may be considerably lower (180-200 $\mathrm{km}$ ). In the non self-consistent computations of the PIONS model used here, conductivities, ion drag and Or emissions are all very strongly enhanced in the F1 region and upper $\mathrm{E}$ region ( 240 down to $150 \mathrm{~km}$ ). Typical auroral electron spectra obtained from the afternoon region of the auroral oval during relatively disturbed periods (Winningham, 1983 ; Evans, private 
comm., 1984) would be consistent with a mean altitude of the volume emission rate as low as $180-200 \mathrm{~km}$, although no fully self-consistent calculations have yet been carried out.

If the mean altitude associated with the volume emission rate of OI $630 \mathrm{~nm}$ is decreased, a given (high) height-integrated wind speed from a GBFPI observation implies a larger total thermospheric momentum and energy content. Similarly, an enhancement of the conductivity to lower altitudes will permit increased momentum coupling for a given ion (and initial neutral) velocity distribution. Eventually it may be possible to study the entire system of mass, energy and momentum coupling from the solar wind into the thermosphere via the magnetosphere and polar ionosphere with selfconsistent models. Until then, it will be difficult to predict the combination of electric fields, precipitalion, currents, heating and ion drag throughout the polar regions during major geomagnetic disturbances.

Establishing a qualitative model of how conductivity increases (via a precipitation mechanism) as required to permit a total exchange of momentum and energy into the thermosphere as direct, if not linear, functions of the solar wind driving of the magnetosphere will be one extremcly interesting and useful product of such a joint model.

We may conclude that the ground based wind observations are, for the dusk auroral oval, a valuable (if non-linear) indicator of the total thermospheric disturbance in that region. It appears also that the wind magnitude in this region is an indicator of the global rates of energy and momentum transfer to the thermosphere from the magnetosphere and thence from the solar wind.

Acknowledgements-The ground-based interferometer at Kiruna is operated in a collaboration between Kiruna Geophysical Institute and UCL, and we would like to thank Ake Steen in particular for assistance in making the observations described here. The majority of the modelling computations were carried out using the CRAY 1S at the University of London Computer Centre. The work was also supported by grants from the U.K. Science Research Council.

The Dynamics Explorer satellites were launched as part of NASA's science programme, and we appreciate many discussions with members of the Dynamics Explorer Science Team. We would like to express our thanks to Dr. B. Tsuratani for the Interplanetary Magnetic Field data from the ISEE-3 Magnetometer Instrument (Dr. E. J. Smith, Principal Investigator).

\section{REFERENCES}

Chiu, Y. T. (1975) An improved phenomenological model of ionospheric density. J. atmos. terr. Phys. 37, 1563.

Dickinson, R. E., Ridley, E. C. and Roble, R. G. (1981) A three-dimensional general circulation model of the thermosphere. J. geophys. Res. 86, 1499.
Fuller-Rowell, T. J. and Rees, D. (1980) A three-dimensional, time-dependent, global model of the thermosphere. $J$. Atmos. Sci. 37, 2545.

Fuller-Rowell, T. J. and Rees, D. (1981) A three-dimensional, time-dependent simulation of the global dynamical response of the thermosphere to a geomagnetic substorm. $J$. atmos. terr. Phys. 43, 701.

Fuller-Rowell, T. J., Quegan, S., Rees, D., Bailey, G. J. and Moffett, R. J. (1984) The effect of realistic conductivities on the high-latitude neutral thermospheric circulation. Planet. Space Sci. 32, 469.

Hays, P. B., Meriwether, J. W. and Roble, R. G. (1979) Nighttime thermospheric winds at high latitudes. $J$. geophys. Res. 84, 1905.

Hays, P. B., Killeen, T. L. and Kennedy, B. C. (1981) The Fabry-Perot interferometer on Dynamics Explorer. Dynamics Explorer-Space Sci. Inst. 5, 395.

Hays, P. B., Killeen, T. L., Spencer, N. W., Wharton, L. E. and Roble, R. G. (1984) Observations of the dynamics of the polar thermosphere. J. geophys. Res. 89, 5597.

Heppner, J.P. (1977) Empirical models of high latitude electric fields. J. geophys. Res. 82, 1115.

Heppner, J. P. and Miller, M. L. (1982) Thermospheric winds at high latitudes from chemical release observations. $J$. geophys. Res. 87, 1633.

Heppner, J. P. and Maynard, N. C. (1983) A paper presented at the Chapman Conference in Virginia on March 1983.

Hernandez, G. and Roble, R. G.(1978a) Relationship between midlatitude thermospheric winds and the time rate of change of D(st). Geophys. Res. Lett. 5, 835 .

Hernandez, G. and Roble, R. G. (1978b) Observations of largescale thermospheric waves during geomagnetic substorms. J. geophys. Res. 83, 5531 .

Hernandez, G. and Roble, R. G. (1982) Thermospheric response to geomagnetic storms. $J$. geophys. Res. 87, 9181.

Killeen, T. L., Hays, P. B., Spencer, N. W. and Wharton, L. E. (1982) Neutral winds in the polar thermosphere as measured from Dynamics Explorer. Geophys. Res. Lett. 9, 957.

Killeen, T. L., Hays, P. B., Spencer, N. W. and Wharton, L. E. (1983) Neutral winds in the polar thermosphere as measured from Dynamics Explorer. Adv. Space Res. 2, 133.

Lloyd, K. H., Low, C. H., McAvaney, B. J., Rees, D. and Roper, R. G. (1972) Thermospheric observations combining chemical seeding and ground-based techniques - I. Winds, turbulence, and the parameters of the neutral atmosphere. Planet. Space Sci. 20, 761.

Maynard, N. C., Heppner, J. P. and Engeland, A. (1982) Intense, variable electric fields at ionospheric altitudes in the high latitude regions as observed by DE-2. Geophys. Res. Lett. 9,981.

Meriwether, J. W., Heppner, J. P, Stolarik, J. D. and Wescott, E. M. (1973). Neutral winds above $200 \mathrm{~km}$ at high latitudes. J. geophys. Res. 78,6643 .

Meriwether, J. W., Tepley, C. A., Price, S. A. Hays, P. B. and Cogger, L. L. (1983) Remote ground-based observations of terrestrial airglow emissions and thermospheric dynamics at Calgary, Alberta. Opt. Engng (in press).

Mikkelsen, I. S. Jorgensen, T. S., Kelley, M. C., Larsen, M. F, Pereira, E. and Vickery, J, (1981) Neutral winds and electric fields in the dusk auroral oval-1. Measurements. $J$. geophys. Res. 86, 1513.

Quegan, S., Bailey, G. J., Moffett, R. J., Heelis, R. A., FullerRowell, T. J., Recs, D. and Spiro, R. W. (1982) A theoretical study of the distribution of ionization in the high latitude ionosphere and the plasmasphere: first results on the mid- 
latitude trough and the light-ion trough. J.atmos. terr. Phys. 44, 619 .

Rees, D. (1971a) Ionospheric winds in the auroral zone. $J . B r$. Interplanet. Soc. $24,233$.

Rees, D. (1971b) Upper atmosphere neutral temperature profiles in the auroral zone 1968-1970. Planet. Space Sci.19, 233.

Rees, D., Fuller-Rowell, T. J. and Smith, R. W. (1980) Measurements of high latitude thermospheric winds by rocket and ground-based techniques and their interpretation using a three-dimensional, time-dependent dynamical model. Planet. Space Sct. 28, 919.

Rees, D., Rounce, P. A., Charleton, P., Fuller-Rowell, T. J., McWhirter, I. and Smith, K. (1981) Mesospheric and thermospheric winds during the Energy Budget Campaign: Ground-based Fabry-Perot observation supported by the dynamical limulations with a three-dimensional, timedependent thermospheric model. Extended abstract, in BMFT-FB-W 81-052: Sounding Rocket Program Aeronomy project: Energy Budget Campaign 1980 Experiment Summary (Edited by Offermann, D, and Thrane, E. V.), p. 161.

Rees, D., Rounce, P. A., Charleton, P., Fuller-Rowell, T. J., McWhirter, I. and Smith K. (1982) Thermospheric winds during the Energy Budget Campaign: Ground-based Fabry-Perot observations supported by dynamical simulations with a three-dimensional, time-dependent thermospheric model. J. Geophys. 50, 202.

Rees, D., Fuller-Rowell, T. I, Gordon, R., Killeen, T. L., Hays, P. B. Wharton, L. E. and Spencer, N. W. (1983a) A comparison of wind observations of the upper thermosphere from the Dynamics Explorer satellite with the predictions of a global time-dependent model. Planet. Space Sci. 31, 1299.

Rees, D., Charleton, P., Lloyd, N., Steen, A. and Witt, G. (1983b) Interferometeric and Doppler imaging studies of the auroral thermosphere from Kiruna Geophysical Institute. Proc. VIth ESA Symposium on Rocket and Balloon Programmes (ESA SP-183), 53-57.

Rees, D., Charleton, P., Carlson, M. and Rounce, P. A. (1984a) High latitude thermospheric circulation during the Energy Budget Campaign. J. atmos. terr. Phys. (in press).

Rees, D., Fuller-Rowell, T. I., Gordon, R., Smith, M. E. Heppner, J. P., Maynard, N. C., Spencer, N. W., Wharton, L. W., Hays, P. B. and Killeen, T. L. (1984b) A theoretical and empirical study of the response of the high latitude thermosphere to the sense of the " $Y$ " component of the interplanetary magnetic field. Planet. Space Sci. (to be submitted).

Roble, R. G. and Rees, M. H. (1977) Time-dependent studies of the aurora : effects of particle precipitation on the dynamic morphology of ionospheric and atmospheric properties. Planet. Space Sci. $25,991$.

Roble, R. G., Dickinson, R. E. and Ridley, E. C. (1982) Global circulation and temperature structure of the thermosphere with high-latitude plasma convection. J. geophys. Res. 87, 1599.

Roble, R. G., Dickinson, R. E., Ridley, E. C., Emery, B. A., Hays, P. B., Killeen, T. L. and Spencer, N. W. (1983) The high latitude circulation and temperature structure of the thermosphere near solstice. Planet. Space Sci. 31, 1479.

Smith, M. F. (1984) A study of the momentum and energy sources in the thermosphere using a global model. Ph.D. Thesis, University College London.

Spencer, N. W., Wharton, L. E., Niemann, H. B., Hedin, A. E., Carignan, H. R. and Maurer, J. C. (1981) The Dynamics.
Explorer wind and temperature spectrometer. Space Sci. Inst. 5, 417.

Spencer, N. W., Wharton, L. E., Carignan, G. R. and Maurer, J. C. (1982) Thermosphere zonal winds, vertical motions and temperature as measured from Dynamics Explorer. Geophys. Res. Lett. 9,953.

Spiro, R. W., Reiff, P. F. and Maher, L. J. (1982) Precipitating electron energy flux and auroral zone conductances-an empirical model. J. geophys. Res. 87, 8215 .

Volland, H. (1978) A model of the magnetospheric electric convection field. J. geophys. Res. 83, 2695.

\section{APPENDIX}

THE SOLAR AND GLOMAGNETIC INPUT CONDITIONS FOR THE THREE IONOSPHERIC MODELS AND FOR THE 3D-TD MODEL, FOR 21 DECEMBER

\begin{tabular}{lcc}
\hline \multicolumn{3}{c}{ Solar energy inputs } \\
u.v. & e.u.v. \\
\hline Northern Hemisphere (winter) & 3.0 & 0.72 \\
Southern Hemisphere (summer) & 6.6 & 1.61 \\
\hline
\end{tabular}

All numbers are in units of 10(11) $\mathrm{W}$.

Ionospheric Model 1-The Chiu Ionosphere

Global ionosphere: Chiu (1975).

Particle heating: None.

Particle ionisation: None.

Joule heating due to polar electric fields and Chiu ionosphere only.

\section{lonospheric Model 2-The Sheffield Lonosphere}

Global ionosphere: Chiu (1975) at low latiludes, merged with a polar model spatially scaled to the dimensions of the "Sheffield" model described by Quegan et al. model at high geomagnetic latitudes.

Particle heating: Polar cusp-1 erg $\mathrm{cm}^{-2}$ at $100 \mathrm{eV}$, plus Polar cap- $0.5 \mathrm{erg} \mathrm{cm}^{-2}$ at $100 \mathrm{eV}$, Total 0.65 (11) W global.

Particle ionisation: Plasma densities related to precipitation used in the self-consistent "Sheffield" model, no further account taken of ionisation due to soft electrons introduced as heat sources in polar cap and cusp.

Joule heating: Due to polar electric field and plasma densities of the "Sheffield" model.

Note the early version of the "Sheffield" model used here strongly augments the $F$ region ionosphere above the levels of the "Chiu" model. However, it actually predicts rather lower electron densities in the winter polar $E$ region than does the "Chiu" model, since the appropriate code to cope with molecular ions is not included in this early version of the "Sheffield" model. This has the effect of reducing the heightintegrated Pedersen conductivity, and thus the total Joule heating in the winter polar region. High altitude friction heating of neutrals is enhanced in the "Sheffield" model compared with the "Chiu" model, and thus neutral temperature above $200 \mathrm{~km}$ is increased.

Ionospheric Model 3 - Chiu low latitude ionosphere merged with PIONS (used for M4 and MS simulations)

Global ionosphere: Chiu (1975) at low latitudes, merged with PIONS model at high geomagnetic latitudes. 
Particle heating:

$$
\begin{aligned}
& \text { Polar cusp- } \quad 2 \mathrm{erg} \mathrm{cm}^{-2} \text { at } 500 \mathrm{eV} \text {, and } \\
& 2 \mathrm{erg} \mathrm{cm}^{-2} \text { at } 100 \mathrm{eV} \text {. } \\
& \text { Polar cap- } \quad 1 \mathrm{erg} \mathrm{cm}^{-2} \text { at } 500 \mathrm{eV} \text {. } \\
& \text { PM auroral oval- } 5 \mathrm{erg} \mathrm{cm}^{-2} \text { at } 500 \mathrm{eV} \text {, }
\end{aligned}
$$

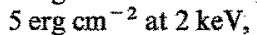

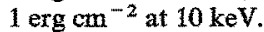

$$
\begin{aligned}
& \text { AM auroral oval- } 10 \mathrm{erg} \mathrm{cm}^{-2} \text { at } 1 \mathrm{keV} \text {, } \\
& 5 \mathrm{erg} \mathrm{cm}^{-2} \text { at } 5 \mathrm{keV} \text {. }
\end{aligned}
$$

$$
\begin{array}{ll}
\text { Midnight oval- } \quad \begin{array}{l}
10 \mathrm{erg} \mathrm{cm}^{-2} \text { at } 1 \mathrm{keV}, \\
125 \mathrm{erg} \mathrm{cm}^{-2} \text { at } 5 \mathrm{keV} .
\end{array}
\end{array}
$$

Particle ionisation: Polar cusp and polar cap ionisation related to Particle heat input by PIONS model.

Joule heating: Polar electric field and ionospheric plasma density as augmented by PIONS computation of effect of magnetospheric electron precipitation.

Joule heating for the steady-state simulations.Values given for: Northern Hemisphere/Southern Hemisphere.

\begin{tabular}{lcccc}
\hline Model & Comparison & M1 & M2 & M3 \\
& A-Chiu & V2-Sheffeld & LEF-Chiu & LEF-Sheffield \\
Date & 21 Dec. & 21 Dec. & 21 Dec. & 21 Dec. \\
00 UT & $0.12 / 1.2$ & $0.28 / 0.94$ & $0.70 / 2.82$ & $0.64 / 1.81$ \\
06 UT & $0.10 / 1.2$ & $0.29 / 1.08$ & $0.65 / 2.9$ & $0.56 / 2.0$ \\
12 UT & $0.13 / 0.8$ & $0.29 / 0.72$ & $0.90 / 1.15$ & $0.77 / 0.95$ \\
18 UT & $0.18 / 0.7$ & $0.35 / 0.72$ & $1.38 / 1.14$ & $1.00 / 0.90$ \\
Particle Heating for the steady-state simulations. & & 0.0 & 0.0 \\
\hline
\end{tabular}

Input is in units of $10(11) \mathrm{W}$.

Joule and Particle Heating for the time-dependent simulations.

\begin{tabular}{cccc}
\hline Model & $\begin{array}{c}\text { Particles } \\
\text { (global) }\end{array}$ & $\begin{array}{c}\text { Joule } \\
\text { (north) }\end{array}$ & $\begin{array}{c}\text { Joule } \\
\text { (south) }\end{array}$ \\
M4(12-14.5 UT) & $4.2(11)$ & $3.4(11)$ & $5.0(11)$ \\
M5(14.4-16.5 UT) & $4.2(11)$ & $3.4(11)$ & $\mathbf{4 . 6 ( 1 1 )}$ \\
\hline
\end{tabular}

Input is in units of $10(11) \mathrm{W}$. 